\title{
Halogen bonds involved in binding of halogenated ligands by protein kinases
}

\author{
Jarosław Poznański ${ }^{\circledR}$, Maria Winiewska', Honorata Czapinska ${ }^{1,2}$, Anna Poznańska ${ }^{3}$ and \\ [David Shugar
}

IInstitute of Biochemistry and Biophysics PAS, Warszawa, Poland; ${ }^{2}$ International Institute of Molecular and Cell Biology, Warszawa, Poland; ${ }^{3}$ Department - Center of Population Health Monitoring and Analysis, National Institute of Public Health - National Institute of Hygiene,

Warszawa, Poland

\begin{abstract}
Analysis of 664 known structures of protein kinase complexes with halogenated ligands revealed 424 short contacts between a halogen atom and a potential protein $\mathrm{X}$-bond acceptor, the topology and geometry of which were analyzed according to the type of a halogen atom $(\mathrm{X}=\mathrm{Cl}, \mathrm{Br}, \mathrm{I})$ and a putative protein $\mathrm{X}$-bond acceptor. Among 236 identified halogen bonds, the most represented ones are directed to backbone carbonyls of the hinge region and may replace the pattern of ATP-like hydrogen bonds. Some halogen- $\pi$ interactions with either aromatic residues or peptide bonds, that accompany the interaction with the hinge region, may possibly enhance ligand selectivity. Interestingly, many of these halogen- $\pi$ interactions are bifurcated. Geometrical preferences identify iodine as the strongest $\mathrm{X}$-bond donor, less so bromine, while virtually no such preferences were observed for chlorine; and a backbone carbonyl as the strongest X-bond acceptor. The presence of a halogen atom in a ligand additionally affects the properties of proximal hydrogen bonds, which according to geometrical parameters get strengthened, when a nitrogen of a halogenated ligand acts as the hydrogen bond donor.
\end{abstract}

Key words: halogen bonding, protein kinase, ligand binding, PDB screening

Received: 15 July, 2015; revised: 11 February, 2016; accepted:

11 March, 2016; available on-line: 20 April, 2016

\section{INTRODUCTION}

Post-translational modifications (PTMs), both reversible and irreversible, may affect intracellular localization of proteins, regulate their interactions with protein or non-protein partners, modulate their catalytic activity, or select some of them for degradation. In general, PTMs increase proteome diversity by at least an order of magnitude, when compared to the transcriptome, and even more so relative to the genome. They also enable rapid response or adaptation to extracellular factors, contributing to signal transduction and regulation of numerous cellular pathways. The most frequent modifications include glycosylation, lipidation, methylation, N-acetylation, S-nitrosylation and sumoylation. A particular role is played by reversible protein phosphorylation. The residues most susceptible to phosphorylation are serine, threonine and tyrosine, less frequently histidine (Klumpp \& Krieglstein, 2002; Besant et al., 2003; Steeg et al., 2003; Besant \& Attwood, 2005; Ciesla et al., 2011), and rarely aspartate (Wagner \& Vu, 2000; Lapek et al., 2015), cysteine (Pannifer et al., 1998; Feng et al., 2008), lysine (Mat- thews, 1995; Khorasanizadeh, 2004; Besant et al., 2009) or arginine (Fuhrmann et al., 2009; Elsholz et al., 2012). Protein kinases, which catalyze phosphorylation of proteins, display a large spectrum of substrate specificities. Most use ATP as a phosphate donor, albeit some may accept GTP (Ventimig \& Wool, 1974).

Protein kinases are attractive molecular targets for drug design (Cohen, 2002), since they are playing key roles in the regulation of many cellular processes, including the cell cycle, growth and apoptosis. To date, most promising protein kinase inhibitors are small ATP-competitive molecules (Zhang et al., 2009; Fabbro, 2015), which bind at the highly conserved ATP-binding site. To enhance target selectivity, some designed ligands are large enough to interact also with other functional sites of a kinase, i.e. bi-substrate inhibitors bind simultaneously at the ATP and substrate-binding sites (Parang et al., 2001; Parang \& Cole, 2002; Fischer, 2004; Gower et al., 2014). Furthermore, some ligands forming a covalent bond with the kinase-specific nucleophilic residue located within the ATP-binding pocket have been developed (Liu et al., 2013). Other options to improve selectivity include non-ATP-competitive inhibitors (Harrison et al., 2008; Battistutta, 2009; Kirkland \& McInnes, 2009; Garuti et al., 2010), such as allosteric ones (Bogoyevitch \& Fairlie, 2007; Lamba \& Ghosh, 2012; Cowan-Jacob et al., 2014), some of which preferably bind to the "DFGout" conformation of a kinase, stabilizing its inactive conformation (Dietrich et al., 2010; Zhao et al., 2014).

Nonetheless, most of the currently used protein kinase inhibitors locate, at least partially, in the ATP-binding pocket. These ligands must mimic the overall properties of the ATP molecule, i.e. they are locally flat, preferably aromatic, and capable of hydrogen bond formation and efficient electrostatic interactions with residues that form the protein kinase ATP-binding site. According to the Lock-and-Key analogy originally postulated in 1894 by Fischer, and further extended to the Induced-Fit Theory (for review see Koshland, 1994), which is a biochemical equivalent of the Pauli exclusion principle: a low-mass ligand should fit to a binding site attainable for ligands in the solvent phase. Van der Waals (vdW) interactions, both attractive and repulsive, are short-range contacts that control binding events (Barratt et al., 2005), favor-

$\triangle$ e-mail: jarek@ibb.waw.pl

Abbreviations: PTMs, post-translational modifications; vdW, van der Waals; X-bond, halogen bond; PDB, Protein Data Bank; CDF, cumulative distribution function; CSD, Cambridge Structural Database; CK2a, casein kinase 2 alfa subunit; CDK2, Cyclin-dependent kinase 2; TBBt, tetrabromobenzotriazole, TBBz, tetrabromobenzimidazole 
ing the ligands that fit to the protein binding site. Electrostatic interactions between a protein and a ligand are dominated by short contacts between charged groups (known as salt bridges, formally zero order term in multipole expansion of electrostatic interactions). Their contribution to the Gibbs free energy of ligand binding approaches $40 \mathrm{~kJ} / \mathrm{mol}$ (Hendsch \& Tidor, 1994). However, the subsequent moments in multipole expansion related to static (charge-dipole, dipole-dipole, etc) or induced-charge distributions (i.e. Debye and London forces), stacking interactions (electron correlation in proximal $\pi$-electron systems), hydrogen and halogen bonding, may also contribute significantly. The significance of these interactions is well described, with the exception of halogen bonding, the contribution of which is still under debate (Eckenhoff \& Johansson, 1997; Liu et al., 2005; Voth et al., 2007; Memic \& Spaller, 2008; Kraut et al., 2009; Zou et al., 2009; Hauchecorne et al., 2010; Sarwar et al., 2010; Carter \& Ho, 2011; Hardegger et al., 2011; Aakeroey et al., 2013; Poznanski et al., 2014), with estimates of the free energy of an individual X-bond varying from 0.8 (Sarwar et al., 2010) up to $30 \mathrm{~kJ} / \mathrm{mol}$ (Voth et al., 2007).

Halogen bonding (X-bond) has been identified in many crystal structures of low-mass compounds and their supramolecular ensembles (for review see Metrangolo et al., 2008), and more recently in complexes of biomolecules with halogenated ligands (Auffinger et al., 2004; Voth \& Ho, 2007; Rendine et al., 2011). Specific interactions between the ligand halogen atoms $(\mathrm{Cl}, \mathrm{Br}$, I) and the electron pairs of an oxygen/nitrogen/sulfur/ $\pi$-electron system have been described, based largely on the observation that the distance between a halogen atom and its electron-donating partner, $\mathrm{d}_{\mathrm{X}} \cdots_{\mathrm{Acc}}$, is significantly shorter than the sum of their vdW radii (Fig. 1A). Fluorine, because of its high electronegativity, is a very poor halogen bond donor (Politzer et al., 2007), but it may act as an efficient hydrogen bond acceptor (Howard et al., 1996; Dunitz, 2004)

The role of halogenated ligands in biological systems has been widely reviewed, amongst others by Auffinger et al., 2004, Parisini et al., 2011, Rendine et al., 2011, Voth et al., 2007, Voth et al., 2009, Scholfield et al., 2013, Wilcken et al., 2013, Persch et al., 2015 and also by us (Poznanski \& Shugar, 2013; Poznanski et al., 2014). These systematic structural studies show numerous examples of halogen bonds formed between a ligand and a protein electron-donating group. The geometry of these halogen bonds has been well described, with a preference for the $\mathrm{X} \cdots$ Acc- $\mathrm{C}\left(\theta^{A}\right)$ angle of $160^{\circ}$, roughly resembling that of a hydrogen bond (Fig. 1), albeit the distributions of $\theta^{\mathrm{x}}$ and $\theta^{\mathrm{D}}$ angles differ significantly. It should however be noted that the distribution of $\theta^{\mathrm{A}}$ and $\theta^{\mathrm{D}}$ angles depends on the hybridization of the involved atoms.
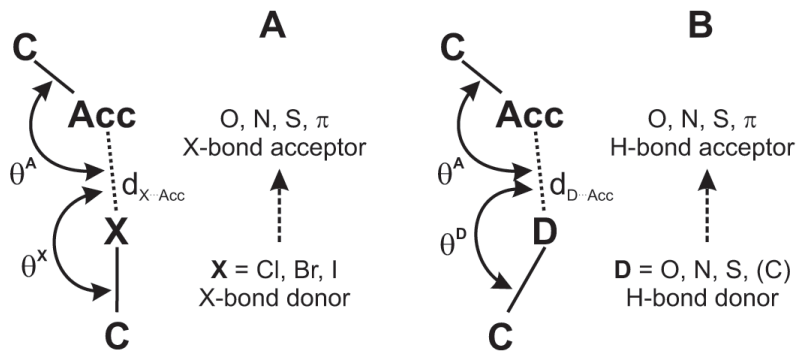

Figure 1. The structural analogy between a halogen $(A)$ and a hydrogen (B) bond.
Numerous natural drugs (Smit, 2004; Wang et al., 2005; Cabrita et al., 2010) and an increasing number of synthetic drug candidates (Hernandes et al., 2010; Pauletti et al., 2010) are halogenated, comprising approximately $20 \%$ of low-mass protein ligands accessible in the Protein Data Bank (PDB), and an even larger number of tested protein kinase inhibitors. The growing number of high-resolution structures of protein kinase-ligand complexes aids in silico development of new inhibitors (Niefind et al., 2009; Ibrahim, 2011; Ibrahim, 2012; Lepsik et al., 2013), many of them halogenated. Understanding the structural requirements for the binding of halogenated ligands, and the estimated contribution of the halogen bonding to the Gibbs free energy of ligand binding is crucial for in silico design of halogenated drugs (Ibrahim, 2012; Jorgensen \& Schyman, 2012; Kolar \& Hobza, 2012; Wang et al., 2014).

Herein we present a detailed analysis of the geometry and topology of short contacts of halogen atoms identified in all complexes of protein kinases with halogenated ligands accessible in the Protein Data Bank. A statistical approach was applied to estimate, independently for $\mathrm{Cl}$, $\mathrm{Br}$ and $\mathrm{I}$ as halogen bond donors, their relative contribution to the free energy of halogen bond formation in protein-ligand systems.

\section{MATERIAL AND METHODS}

Structural data. The Protein Data Bank (PDB) was searched to identify all entries of protein kinases (EC 2.7.10, 2.7.11 and 2.7.12), while histidine protein kinases (2.7.13) were omitted.

Structural analysis. All analyses were performed with the aid of the Yasara Model package (Krieger et al., 2009). For each halogen atom type, all intermolecular ligand-protein contacts were identified, using $4 \AA$ as a threshold for the distance between a halogen atom and a putative halogen bond acceptor. The analysis was further restricted to interactions characterized by the $\mathrm{d}_{\mathrm{x}} \cdots$ Acc distance between a halogen atom and a potential halogen bond acceptor shorter than the sum of their vdW radii. The contacts for which the C-X $\cdots$ Acc angle exceeded $140^{\circ}$ (Fig. 1) were annotated as halogen bonds. Multiple protein molecules in the unit cell, as well as objects displaying multiple partially occupied forms (i.e. side-chain rotamers or ligand locations) were analyzed separately.

Structure validation. The analysis was done with the aid of Coot (Emsley \& Cowtan, 2004; Emsley et al., 2010) and figures with the PyMol program (DeLano \& Lam, 2005). Reliability of the presence, position and identity of solvent molecules in the vicinity of the halogen atoms was assessed in several ways. First, we eliminated all structures with resolution lower than $2 \AA$ and structures with muliple conformations of the halogenated part of the ligand. Next, we manually inspected EDS(Kleywegt et al., 2004) and PDB REDO- (Joosten et al., 2014) generated $F_{o}-F_{c}$ (difference maps indicating disagreement between the observed, $F_{0}$, and calculated, $F_{c}$, electron densities) as well as $2 F_{0}-F_{c}$ electron density maps (maps calculated with model phases and experimental structure factors, with an additional $F_{0}-F_{c}$ correction that counteracts the model bias). Finally we analyzed B-factors, coordination geometry and topology of the solvent molecules in question. Since there were only a few molecules fulfilling all selection criteria, we restricted solvent analysis to high resolution structures $(<2.5 \AA)$ with deposited electron density maps, and excluded all solvent molecules in extremely short contacts with the halogen 
atoms $(<2.5 \AA)$. In all analyzed cases there were ions of molecular weight comparable to water present in the crystallization buffer $\left(\mathrm{Na}^{+}, \mathrm{Mg}^{2+}\right.$ or $\left.\mathrm{NH}_{4}^{+}\right)$. While metal ions should, in principle, be distinguishable from water on the basis of the coordination sphere, it is very hard to tell apart the ammonium ion and water with crystallographic methods, and thus we cannot absolutely exclude polar character of the identified interactions. X-ray radiation induced partial ligand decomposition also cannot be excluded.

Statistical analysis. To overcome the categorization issue, all distributions are presented in a cumulative manner as a CDF (cumulative distribution function), which is the integral of a commonly used distribution function. This form of presentation helps in visual comparison of various distributions of samples of a limited size. Since, according to the Anderson-Darling test (Anderson \& Darling, 1952), most distributions were found to be non-Gaussian (data not shown), the statistical significance of the observed differences was estimated according to the Mann-Whitney U test (Mann \& Whitney, 1947) for comparison of two datasets, and the Kruskal-Wallis H test (Kruskal \& Wallis, 1952) for 3 or more groups. When the above tests did not show statistically significant differences in the location of analyzed distributions, the Kolmogorov-Smirnov two-sample test, much more sensitive for the distribution shape, was applied (Massey, 1951). All analyses were performed using Statistica 10 (StatSoft, 2011). Null hypotheses that given distributions do not differ from each other were tested at a significance level of $\alpha=0.05$, and those with p-values below 0.05 were rejected. The p-values listed in the text are indexed according to the applied method: $\mathrm{p}_{\mathrm{MW}}, \mathrm{p}_{\mathrm{KW}}$ and $\mathrm{p}_{\mathrm{KS}}$ for Mann-Whitney, Kruskal-Wallis and Kolmogorov-Smirnov test, respectively. In general,

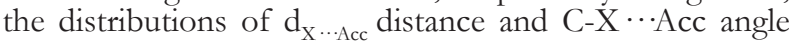
(judged by the smaller-larger principle), were preferably analyzed using Mann-Whitney or Kruskal-Wallis tests, and the $\mathrm{X} \cdots$ Acc-C angle distribution (interpreted in the wider-narrower terms), with the Kolmogorov-Smirnov two-sample test.

\section{RESULTS AND DISCUSSION}

\section{Preferred topology of short contacts between a ligand halogen atom and a protein kinase}

A total number of 424 short contacts between halogen atoms and potential X-bond acceptors was found in 320 of 664 structures of protein kinases in complexes with halogenated ligands. This includes 151 PDB records for protein tyrosine kinases (Enzyme Classification 2.7.10), 386 for protein serine/threonine kinases (EC 2.7.11) and 127 for dual-specificity protein kinases (EC 2.7.12). Short contacts were identified using thresholds calculated individually according to X-bond donor and acceptor types as the sum of their van der Waals (vdW) radii of $1.52,1.55,1.70,1.75,1.80,1.85$ and $1.98 \AA$ for oxygen, nitrogen, carbon, chlorine, sulfur, bromine and iodine, respectively (Bondi, 1964). Overall, 223, 148 and 53 short contacts were identified for chlorine, bromine and iodine atoms attached to a carbon atom (halide ions were excluded from the analysis). This includes, respectively, 102, 88 and 46 interactions fulfilling the distance and angle requirements for a halogen bond (Desiraju et al., 2013). The numbers of identified short contacts and halogen bonds are presented in Table 1. Only three of the highest populated X-bond acceptor types were pre- sent in sufficient numbers to assess the statistical significance of the observed halogen-dependent differences in the parameters describing the halogen bond geometry.

The most targeted protein kinase regions are the $\beta$-sheets of the N-terminal lobes, for which putative acceptors include carbonyl oxygen and/or $\pi$-electrons of a peptide bond; and carbonyls of residues located in the hinge region that are involved in the ATP binding (see Fig. 2 below).

A carbonyl oxygen, in accordance with the PDB screenings (Auffinger et al., 2004; Lu et al., 2009; Hardegger et al., 2011; Parisini et al., 2011), is the most abundant putative acceptor of a halogen bond, contributing, together with an amide nitrogen, to over $50 \%$ of the identified short intermolecular contacts. Due to geometrical reasons, most of the contacts between a halogen atom and a backbone nitrogen accompany interaction(s) with a proximal carbonyl group. There are, however, some structures strictly representing the concept of orthogonal halogen bonds to $\pi$-electrons of the amide group, originally identified by Voth (Voth et al., 2009). In the complex of human CDK2 with a brominated triazole-pyrimidine inhibitor (pdb2c69; Richardson et al., 2006), the separate X-bond to the backbone nitrogen of Glu12 could be identified (Fig. 2A), while in the complex of epidermal growth factor receptor variant with PD168393 (pdb4lrm; Yasuda et al., 2013), the bromine atom makes numerous short orthogonal contacts with $\mathrm{X}$-bond acceptors located in the proximal $\beta$-sheets (Fig. 2B).

Interestingly, the side chain of an aspartate located in the DFG loop may also interact with a halogen atom. This interaction has been rarely identified in the PDB records ( $\mathrm{Lu}$ et al., 2009; Wilcken et al., 2013). However, there are nine PDB structures of protein kinases that display short contacts between a halogen atom and the carboxyl group of this aspartate: CK2 $\alpha$ (pdb1zoh; Battistutta et al., 2005, pdb4bxa, pdb4bxb, pdb4kwp; Cozza et al., 2014), mitogen-activated kinases MAPK14 (pdb3fsf; Goldstein et al., 2011) and MEK1 (pdb4u7z; Robarge et al., 2014, pdb3eqc; Fischmann et al., 2009), BTK kinase (pdb3pj1; Kuglstatter et al., 2011), and serine/threonine protein kinase 10 (pdb4bc6), in most of which the orientation of a C-X bond relative to the proximal carboxyl group deviates from linearity by approximately $40^{\circ}$ (Fig. 2CD).

\section{Halogen bonding with the $\pi$-electron system of an aromatic residue}

Protein kinase sequences include many aromatic residues, some of which are involved in catalysis, either by direct binding of ATP or transfer of the phosphate group. Those located in the vicinity of the ATP-binding site may form short contacts with halogenated ATPcompetitive ligands. The conserved aromatic residues in protein kinases are generally found in the glycinerich loop (Y50 in $\mathrm{CK} 2 \alpha / \mathrm{Y} 15$ in $\mathrm{CDK} 2$ ), hinge region (F113/F80 and Y115/F82), catalytic loop (H154/H125 and H160/Q131), and the DFG-motif (W176/F146). Locations of these residues for protein kinase $\mathrm{CK} 2 \alpha$ are shown in Supplementary Fig. 1. Interestingly, the aromatic residues are not strictly conserved in protein kinases and thus may be targeted by X-bonding to enhance ligand specificity.

Halogen bonding to $\pi$-electron systems is well documented in the Cambridge Structural Database (CSD), but depicted by only a few structures demonstrating the interactions between halogen atoms in organic systems 


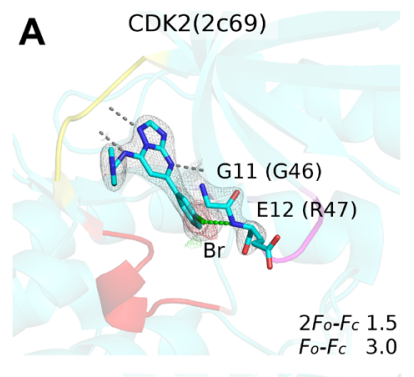

E

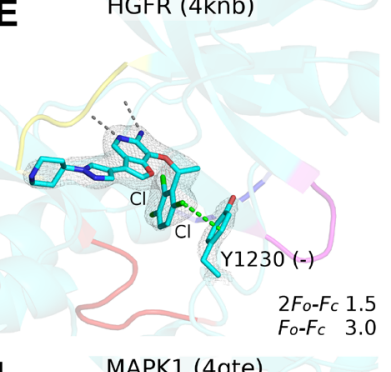

I

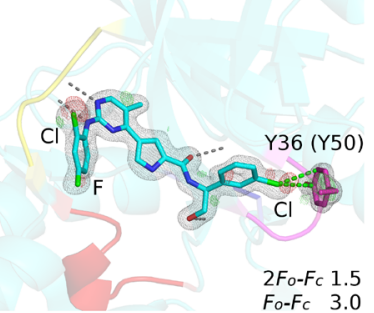

M
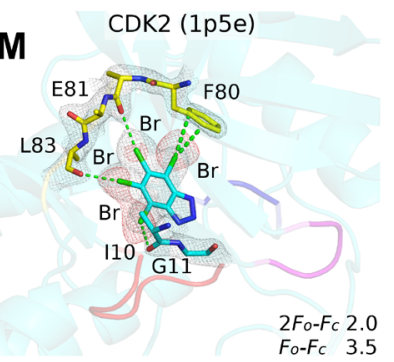

Q

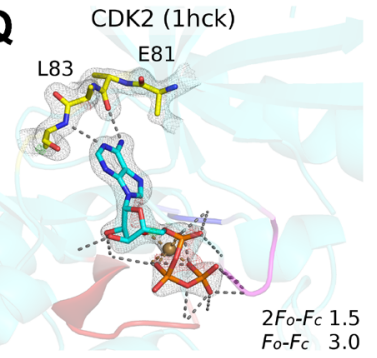

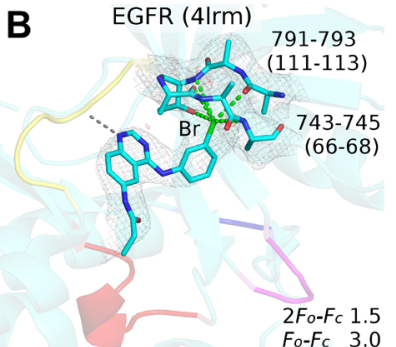

F B-RAF (3tv4)

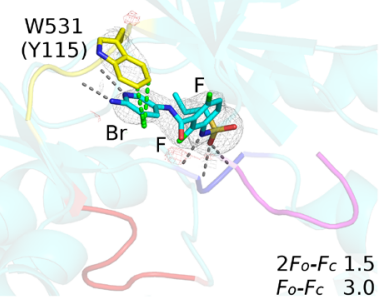

J

CDK2 (2r3q)

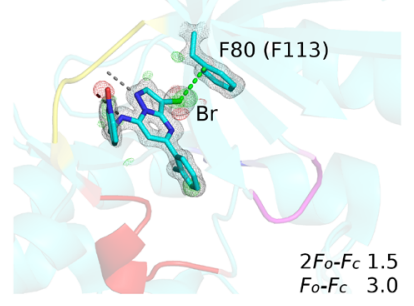

$\mathbf{N}$
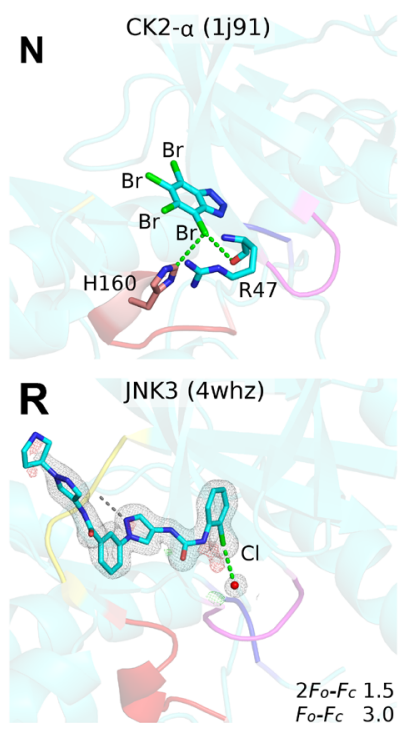

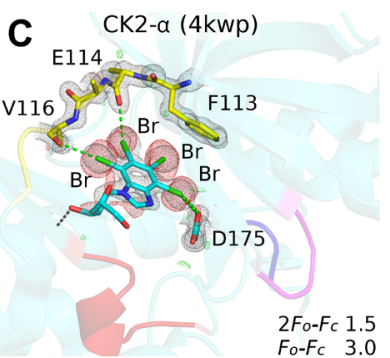

G PIM-1 (4med)

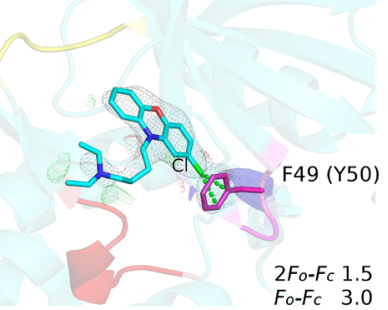

K CK2-a (3kxh)
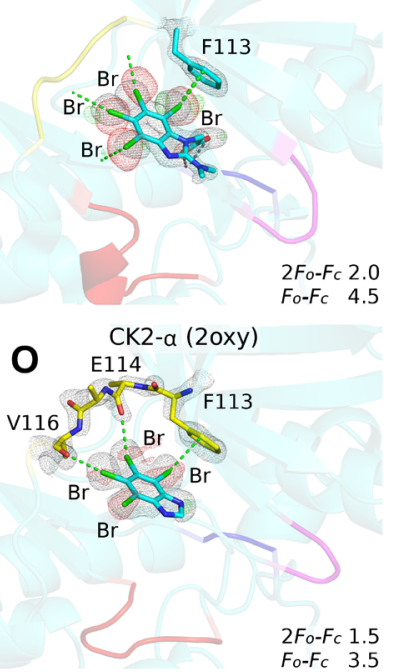

S

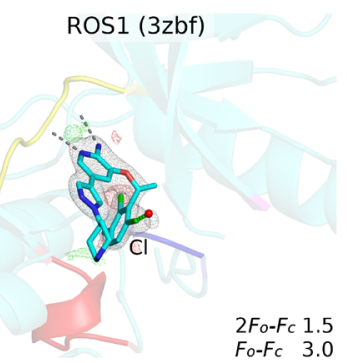

D MAPK14 (3fsf)

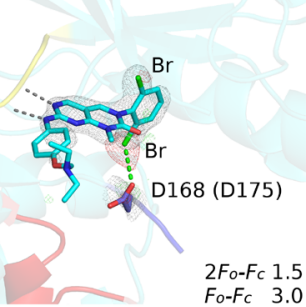

H PKA C- $\alpha$ (4c37)

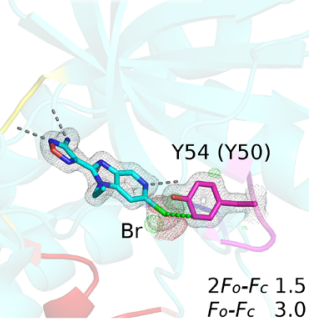

L GSG2 (2vuw)
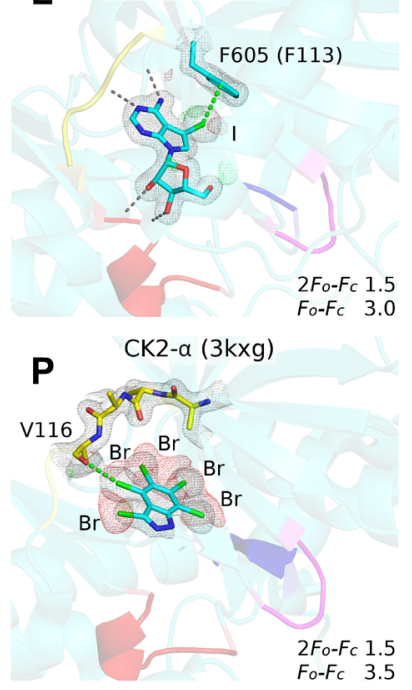

T MELK (4d2w)

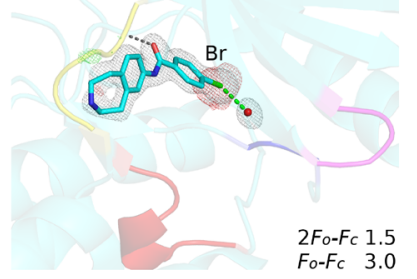

Figure 2. Representative structures of protein kinases in complexes with halogenated ligands that display short contacts between a halogen atom and a protein:

(A, B) contacts orthogonal to the peptide bond; (C, D) unusual interaction between a halogen atom and a proximal aspartate side-chain carboxyl; $(\mathbf{E}, \mathbf{F}) \pi-\pi$ interaction between aromatic rings; $(\mathbf{G}, \mathbf{H})$ parallel orientation of the $\mathrm{C}-\mathrm{X}$ bond and the aromatic ring; $(\mathbf{I}-\mathbf{L})$ halogen bonds between the ligand and an aromatic ring (optimal perpendicular configuration); ( $\mathbf{M}, \mathbf{N}$ ) alternative binding modes of TBBt by two closely related protein kinases, and (N-P) closely related halogenated ligands that substantially differ in their location at the ATP-binding site of protein kinase CK2a; (Q) hydrogen bonding pattern with ATP; (R-T) short contacts between a halogen atom and a solvent molecule. The original pdb codes and protein acronyms are denoted for each structure. The corresponding residues in CK2a are indicated in brackets. The figure includes EDS generated $2 F_{0}-F_{c}$ (grey) and $F_{o}-F_{c}$ (red - negative, green - positive) electron density maps contoured at given rmsd levels (inaccessible for 1j91). The halogen atoms and their short contacts are colored green and the hydrogen bonds and metal-ligand interactions grey. The glycine-rich loop, hinge region, catalytic loop and DFG motif are denoted in magenta, yellow, red and blue, respectively. Panels $\mathbf{M}$ and $\mathbf{S}$ are sligtly rotated with respect to the others and some side chains are omitted for clarity. 
Table 1. Short intermolecular contacts between the halogen atom of a ligand and various types of potential X-bond acceptors identified in 320 PDB structures of protein kinases with halogenated ligands.

The second numbers reported in each cell represent values determined for X..Acc interactions with C-X..Acc angle $>140^{\circ}$.

\begin{tabular}{|c|c|c|c|c|c|c|c|c|c|c|}
\hline \multirow{2}{*}{ X-bond acceptor } & \multicolumn{3}{|c|}{ X-bond donor } & \multirow{2}{*}{ Total } & \multicolumn{3}{|c|}{ Median for X...Acc distance $[\AA ̊]$} & \multicolumn{3}{|c|}{ Median for C-X...Acc angle $\left[^{\circ}\right]$} \\
\hline & $\mathrm{Cl}$ & $\mathrm{Br}$ & I & & $\mathrm{Cl}$ & $\mathrm{Br}$ & 1 & $\mathrm{Cl}$ & $\mathrm{Br}$ & 1 \\
\hline O (backbone) & $88 ; 64$ & $64 ; 52$ & $32 ; 30$ & $184 ; 146$ & $3.15 ; 3.12$ & $3.17 ; 3.12$ & $3.30 ; 3.29$ & $156 ; 159$ & $158 ; 162$ & $173 ; 173$ \\
\hline O (side-chain) & $52 ; 16$ & $10 ; 3$ & $6 ; 2$ & $68 ; 21$ & $3.05 ; 3.10$ & $3.18 ; 3.22$ & $3.25 ; 3.04$ & $105 ; 158$ & $128 ; 146$ & $120 ; 158$ \\
\hline $\mathrm{O}(\text { water })^{*}$ & $39 ; 13$ & $44 ; 15$ & $7 ; 6$ & $90 ; 34$ & $3.13 ; 3.09$ & $3.19 ; 3.04$ & $3.19 ; 3.25$ & $129 ; 164$ & $130 ; 167$ & $145 ; 159$ \\
\hline N (backbone) & $19 ; 2$ & $6 ; 0$ & $0 ; 0$ & $25 ; 2$ & $3.15 ; 3.03$ & $3.39 ;-$ & - & $127 ; 144$ & 110 & - \\
\hline $\mathrm{N}$ (side-chain) & $12 ; 3$ & $1 ; 1$ & $0 ; 0$ & $13 ; 3$ & $3.25 ; 3.11$ & $3.00 ; 3.00$ & - & $127 ; 146$ & $165 ; 165$ & - \\
\hline Aromatic side-chain & $8 ; 3$ & $18 ; 17$ & $4 ; 4$ & $30 ; 24$ & $3.39 ; 3.30$ & $3.89 ; 3.91$ & $4.09 ; 4.09$ & $133 ; 168$ & $159 ; 160$ & $151 ; 151$ \\
\hline S (side-chain) & $5 ; 1$ & $5 ; 0$ & $4 ; 4$ & $14 ; 5$ & $3.10 ; 3.37$ & $3.49 ;-$ & $3.65 ; 3.65$ & $128 ; 160$ & $84 ;-$ & $154 ; 154$ \\
\hline Total & $223 ; 102$ & $148 ; 88$ & $53 ; 46$ & $424 ; 236$ & & & & & & \\
\hline
\end{tabular}

*The identity of the solvent molecule cannot be deduced with $100 \%$ certainty from X-ray crystallographic data

and aromatic groups, shorter than the sum of their van der Waals radii (Reddy et al., 1996; Hubig et al., 2000). Halogen bonds to $\pi$-electron systems have also been identified in complexes of halogenated ligands with proteins, e.g. serine protease Xa (Nazare et al., 2005), farnesyltransferase (Tong et al., 2003), or HIV-1 reverse transcriptase (Das et al., 2004).

Three modes of interaction between a halogen atom and an aromatic system have been identified, based on the orientation of the aromatic ring with respect to a C-X bond, which can be positioned either perpendicular or parallel to the normal vector defined by the plane of the aromatic ring. When a C-X bond is perpendicular to the plane of the aromatic ring (i.e. parallel to the normal vector), the halogen atom may interact either with the center of the $\pi$-electron system (Fig. 3A) or with its rim (Fig. 3B). The mode in which the C-X bond lies over the plane of the aromatic ring (Fig. 3C), does not fulfill the formal geometrical requirements for halogen bonding, since the $\sigma$-hole, located along the C-X axis (Clark et al., 2007), is not directed toward the potential halogen bond acceptor. When a halogen atom is attached to an aromatic moiety, possible $\pi-\pi$ stacking interactions additionally compete with a halogen atom for a proximal $\pi$-electron system (Li et al., 2012).

Screening of structures of protein kinases in complexes with halogenated ligands has evidenced numerous close contacts between halogen atoms and $\pi$-electron systems. Their topology varies, but several groups can be

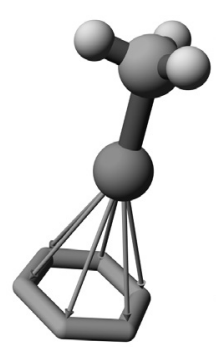

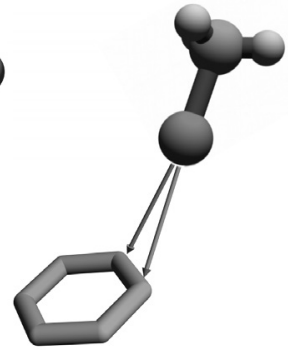

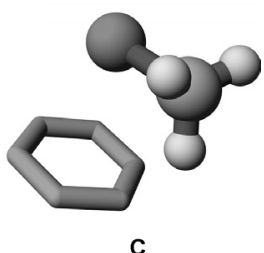

Figure 3. Schematic representation of the perpendicular "over the center" (A), "over the rim" (B) and parallel (C) orientations of bromomethane relative to a proximal benzene aromatic ring. identified. The most abundant short contacts with halogen atoms involve the phenylalanine residue of the hinge region (F113 in $\mathrm{CK} 2 \alpha)$, next is a tyrosine residue located in the glycine-rich loop (Y50), and an aromatic residue from the DFG motif (W176). All structures that display short contacts between a halogen atom and an aromatic ring are collected in Table 2. The representative geometries are shown in Fig. 2E-L. It should be noted, however, that the orientation of a C-X bond with respect to a proximal aromatic ring for numerous identified systems disagrees with the idealized geometry of a halogen bond and instead resembles the parallel arrangement (see Fig. 3C). Thus, the halogenated ligand may be involved in a canonical $\pi-\pi$ interaction with the protein aromatic residue, as shown in Fig. 2E, F for chlorinated and brominated ligands (1RU with hepatocyte growth factor receptor in pdb4knb (Steinig et al., 2013) and TV4 with serine/threonine-protein kinase B-Raf in pdb3tv4 (Wenglowsky et al., 2011), respectively).

In numerous other structures, the C-X $\cdots$ Acc angle also differs substantially from the range of 160$180^{\circ}$ found optimal in CSD (Rosokha \& Kochi, 2008), as shown in Fig. 2G, H for RTX with serine/threonine-protein kinase pim-1 (pdb4med) and Z21 with subunit alpha of cAMP-dependent protein kinase (pdb4c37; Couty et al., 2013). The largest number of short contacts with strongly perturbed geometry is observed for chlorinated ligands ( $>60 \%$ of all identified), in contrast to brominated and iodinated ones, for which the geometry close to optimal is preserved in the majority of analyzed cases (95 and 100\%, respectively). Finally, a total number of 24 halogen bonds to $\pi$-electron aromatic systems, for which all geometrical requirements for efficient halogen bonding are fulfilled, have been identified (Table 2 and Fig. 2I-L).

The most frequently observed halogen bond to the aromatic residue engages the phenylalanine of the hinge region. It is often accompanied by two parallel hydrogen bonds formed with the backbone of the downstream residue (Phe+3), that for polyhalogenated ligands may be substituted by halogen bond(s) to the carbonyl groups of residues $(+1)$ and $(+3)$ (Fig. 2J, L). Alternatively, a halogen- $\pi$ interaction may involve an aromatic residue of the glycine-rich loop, as observed in the complexes of mitogen-activated protein kinase 1 with E57 (pdb4fv6) or VTX-11e (pdb4qte; Chaikuad et al., 2014), and cAMP-dependent protein kinase with $\mathrm{H}-89$ (pdb3vqh; Pflug et al., 2012) or CCT196539 (pdb4c37; Couty et 
Table 2. Short contacts between a halogen atom and an aromatic ring identified in complexes of protein kinases with halogenated ligands together with accompanying short contacts between halogen atoms and solvent molecules.

All contacts marked in bold fulfill the formal definition of an X $\cdots \pi$ halogen bond. The interaction classes are indicated: cen - approximately perpendicular orientation of a C-X bond and the plane of an aromatic ring, and halogen directed towards the center of the ring (see Fig. $3 A$ ); rim - as above but halogen facing the rim of the aromatic ring (Fig. $3 B$ ); $\pi-\pi-$ parallel orientation (Fig. $3 C$ ). Res - resolution, mol protein chain ID in the PDB file, dist. - interatomic distance, $q$ - a projection of the halogen atom on the aromatic ring (closest point), cat loop - catalytic loop.

\begin{tabular}{|c|c|c|c|c|c|c|c|c|c|c|c|c|c|c|}
\hline \multirow{3}{*}{ PDB } & \multirow{3}{*}{$\begin{array}{l}\text { Res } \\
[\AA]]\end{array}$} & \multirow{3}{*}{ Mol } & \multirow{3}{*}{ Residue } & \multirow{3}{*}{ Motif } & \multirow{3}{*}{ Ligand } & \multirow{3}{*}{ Type } & \multicolumn{6}{|c|}{ Aromatic residue } & \multicolumn{2}{|c|}{ Proximal solvent } \\
\hline & & & & & & & \multicolumn{3}{|c|}{ Distance $[\AA ̊]$} & \multicolumn{3}{|c|}{ Angle $\left[^{\circ}\right]$} & \multirow{2}{*}{$\begin{array}{l}\text { Dist }[\AA]] \\
\mathrm{X} \cdot \mathrm{O}\end{array}$} & \multirow{2}{*}{$\begin{array}{l}\text { Angle }\left[^{\circ}\right] \\
\mathrm{CX} \cdot \mathrm{O}\end{array}$} \\
\hline & & & & & & & $X \cdot C$ & X.rim & $X \cdot q$ & $C X \cdot q$ & $C X \cdot \cdot \pi$ & $\pi \cdot \pi$ & & \\
\hline \multicolumn{15}{|c|}{ Chloride } \\
\hline 3nux & 2.70 & A & F98 & hinge & $3 N V$ & rim & 3.30 & 3.44 & 3.91 & 156 & 77 & 77 & 3.61 & 96 \\
\hline 3owk & 1.80 & A & F113 & hinge & $18 \mathrm{E}$ & rim & 3.27 & 3.24 & 3.64 & 132 & 35 & 35 & 3.01 & 127 \\
\hline $4 \mathrm{a} 06$ & 2.00 & A & F157 & hinge & A06 & rim & 3.02 & 3.04 & 3.19 & 130 & 37 & 85 & & \\
\hline $4 a 07$ & 1.85 & $A$ & F157 & hinge & AZ7 & rim & 2.98 & 2.98 & 3.17 & 134 & 46 & 83 & & \\
\hline $4 f v 6$ & 2.50 & A & Y34 & Gly-loop & E57 & cen & 3.42 & 3.37 & 3.27 & 168 & 81 & 81 & 3.87 & 80 \\
\hline $4 \mathrm{knb}$ & 2.40 & $\mathrm{C}$ & Y1230 & cat loop & $1 R U$ & $\pi-\pi$ & 3.37 & 3.36 & 3.47 & 84 & 10 & 25 & & \\
\hline $4 \mathrm{med}$ & 2.80 & A & F49 & Gly-loop & RTX & rim & 3.16 & 3.25 & 3.64 & 111 & 40 & 46 & & \\
\hline \multicolumn{15}{|c|}{ Bromide } \\
\hline $1 \mathrm{~h} 08$ & 1.80 & A & F80 & hinge & BWP & rim & 3.45 & 3.43 & 4.00 & 163 & 37 & 49 & 3.11 & 116 \\
\hline $1 \mathrm{p} 5 \mathrm{e}$ & 2.22 & A & F80 & hinge & TBS & rim & 3.26 & 3.23 & 3.49 & 154 & 44 & 45 & 2.91 & 122 \\
\hline $1 \mathrm{p} 5 \mathrm{e}$ & 2.22 & C & F80 & hinge & TBS & rim & 3.24 & 3.26 & 3.68 & 175 & 55 & 58 & 3.03 & 112 \\
\hline 1zoe & 1.77 & A & F113 & hinge & K25 & rim & 3.49 & 3.55 & 3.93 & 163 & 44 & 47 & 2.87 & 126 \\
\hline $1 z \circ g$ & 2.30 & A & F113 & hinge & K37 & $\mathrm{rim}$ & 3.23 & 3.19 & 3.53 & 154 & & & 3.14 & 106 \\
\hline $1 \mathrm{zog}$ & 2.30 & A & F113 & hinge & K37 & $\mathrm{rim}$ & 3.47 & 3.49 & 3.87 & 159 & 42 & 43 & 3.20 & 115 \\
\hline 1zoh & 1.81 & A & F113 & hinge & K44 & rim & 3.51 & 3.50 & 3.92 & 159 & 41 & 42 & & \\
\hline $20 x y$ & 1.81 & A & F113 & hinge & K17 & $\mathrm{rim}$ & 3.66 & 3.59 & 3.91 & 154 & & & 2.90 & 126 \\
\hline $20 x y$ & 1.81 & B & F113 & hinge & K17 & rim & 3.53 & 3.51 & 3.81 & 156 & 44 & 45 & 3.06 & 118 \\
\hline $2 \mathrm{r} 3 \mathbf{j}$ & 1.65 & A & F80 & hinge & SCJ & rim & 3.41 & 3.41 & 3.95 & 163 & 39 & 60 & & \\
\hline 2 r3I & 1.65 & A & F80 & hinge & SCW & rim & 3.51 & 3.49 & 4.05 & 160 & 36 & 57 & & \\
\hline $2 r 3 q$ & 1.35 & A & F80 & hinge & $5 S C$ & $\mathrm{rim}$ & 3.52 & 3.55 & 3.96 & 155 & 35 & 51 & 3.01 & 154 \\
\hline $3 \mathbf{k x h}$ & 1.70 & A & F113 & hinge & K66 & rim & 3.35 & 3.38 & 3.53 & 165 & 57 & 59 & & \\
\hline $3 \mathbf{k x m}$ & 1.75 & A & F113 & hinge & K74 & rim & 3.49 & 3.50 & 3.81 & 155 & 42 & 42 & 3.02 & 117 \\
\hline $3 v q h$ & 1.95 & A & F54 & Gly-loop & IQB & rim & 3.26 & 3.24 & 3.70 & 162 & 65 & 65 & & \\
\hline $4 b \times a$ & 1.75 & A & F113 & hinge & JRJ & rim & 3.47 & 3.47 & 3.97 & 163 & 42 & 44 & & \\
\hline $4 c 37$ & 1.70 & A & Y54 & Gly-loop & Z21 & rim & 3.50 & 3.54 & 3.75 & 116 & 30 & 41 & 3.19 & 117 \\
\hline \multicolumn{15}{|l|}{ lodide } \\
\hline 2vuw & 1.80 & A & F605 & hinge & $5 I D$ & rim & 3.52 & 3.60 & 4.14 & 153 & 43 & 47 & 3.71 & 137 \\
\hline $3 i q 7$ & 2.00 & A & F605 & hinge & 5ID & rim & 3.53 & 3.62 & 4.12 & 151 & 46 & 52 & 3.78 & 134 \\
\hline 4mne & 2.85 & $\mathrm{H}$ & $\mathrm{H} 87$ & cat loop & 573 & rim & 3.53 & 3.53 & 3.82 & 141 & 52 & 61 & & \\
\hline 4ouc & 1.90 & A & F605 & hinge & $5 I D$ & rim & 3.59 & 3.63 & 4.06 & 151 & 43 & 50 & 3.67 & 139 \\
\hline
\end{tabular}

al., 2013). All these ligands also make hydrogen bond(s) with the $(+3)$ residue of the hinge region.

Interestingly, a C-X $\cdots \pi$ halogen bond is frequently accompanied by a parallel interaction of the halogen atom with a proximal solvent molecule, identified in over $50 \%$ of the analyzed structures (see Table 2). For ligands forming an $\mathrm{X}$-bond with the hinge region, location of this solvent molecule is highly conserved, and the distance between the halogen atom and the oxygen atom (in case this solvent molecule is interpreted as water) is substantially shorter than the vdW limit. This may represent a possible example of a bifurcated halogen bond identified in crystals of small organic compounds (Lu et al., 2006; Carlsson et al., 2015; Novak et al., 2015). The observed $\mathrm{C}-\mathrm{X} \cdots \mathrm{O}_{\text {wat }}$ angle of approximately $120^{\circ}$ (see Table 2) strictly corresponds to a minute maximum identified in the distribution of the $\mathrm{C}-\mathrm{X} \cdots \mathrm{O}$ angles by Scholfield (Scholfield et al., 2013), however it seems to be too far from the optimal $160-180^{\circ}$ found for a plausible halogen bond in previous screenings of the PDB 

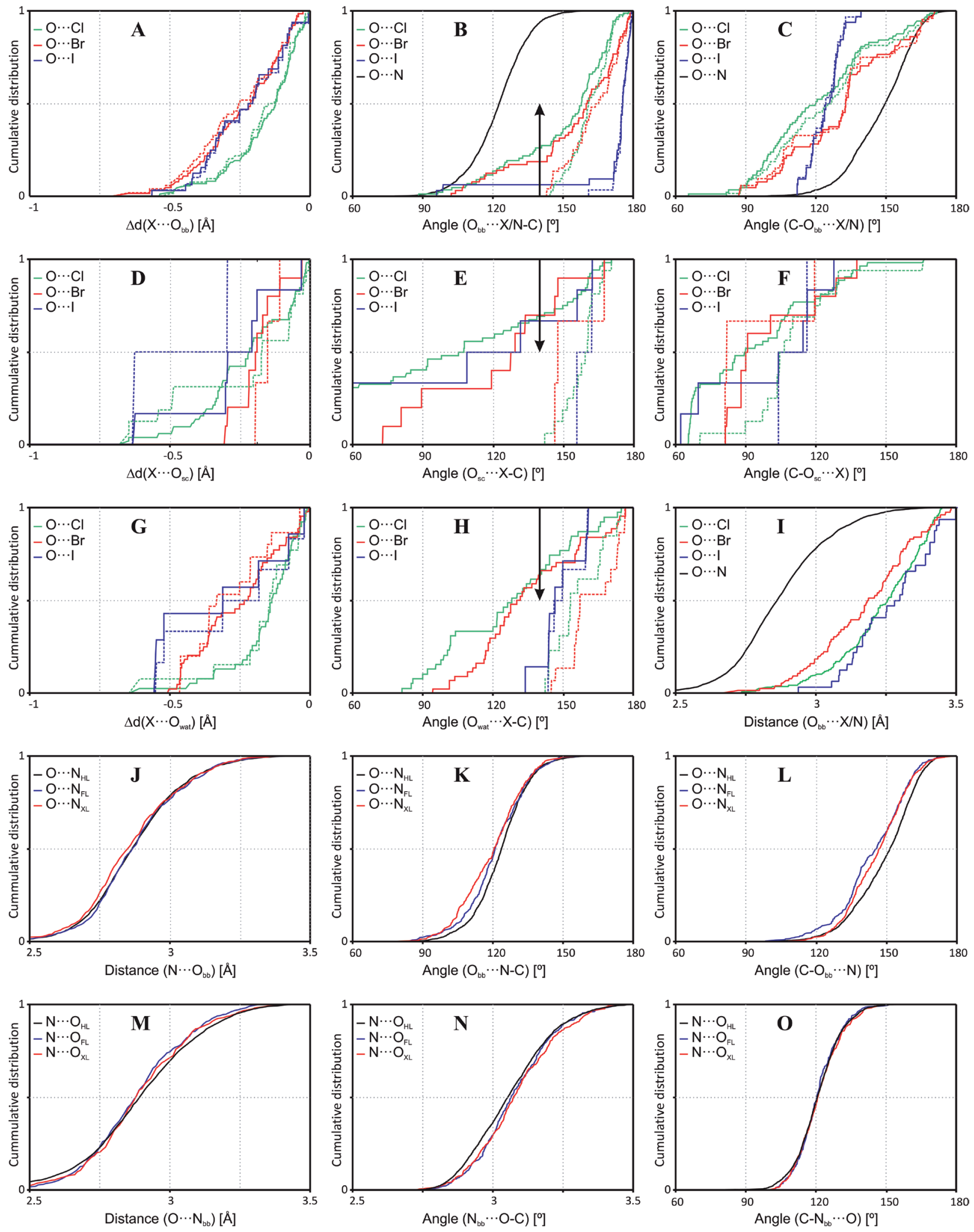

Figure 4. Cumulative distributions of the parameters describing the geometry of an interaction between a halogenated ligand and a backbone carbonyl $(A-C, I)$, side-chain oxygen (D-F) and a water molecule $(\mathbf{G}-\mathrm{H})$, determined separately for each halogen type.

As a reference, the distributions for an $\mathrm{H}$-bond between a non-halogenated ligand and a backbone carbonyl are presented as black lines

in $(\mathbf{B}, \mathbf{C}, \mathbf{I})$, and additionally shown for non-halogenated $(\mathrm{HL})$, fluorinated $(\mathrm{FL})$ and otherwise halogenated $(\mathrm{XL})$ ligands acting either as donors $(\mathbf{J}-\mathbf{L})$ or acceptors $(\mathbf{M}-\mathbf{O})$ of an $\mathrm{H}$-bond formed with a protein backbone (only those between nitrogen and oxygen). Chopped lines in $(\mathbf{A}-\mathbf{H})$ represent cumulative distributions obtained for $\theta^{\mathrm{x}}$ restricted to the range of $140-180^{\circ}$, indicative of $X$-bond formation, which is denoted by vertical arrows (B, E, H). 
(Auffinger et al., 2004; Parisini et al., 2011; Poznanski \& Shugar, 2013; Scholfield et al., 2013) and CSD (Metrangolo et al., 2005). Solvent molecules proximal to an $\mathrm{X}$-bond have also been identified in other protein-ligand complexes (Beale et al., 2013), but this type of three-body interaction has to date not been listed in the IUPAC definition of a halogen bond (Desiraju et al., 2013). Moreover, a water molecule itself does not fulfill the actual IUPAC definition of an X-bond acceptor.

\section{Halogen bond between a ligand and the backbone carbonyl oxygen}

The shortest distances between a halogen atom and the carbonyl oxygen are observed for bromine (median of $3.19 \AA$ calculated for all halogen-oxygen contacts shorter than $3.5 \AA$ ), whereas, despite the large difference in $\mathrm{vdW}$ radii, the distributions for chlorine and iodine donors are almost identical (medians of 3.25 and $3.28 \AA$, respectively). This, in view of the vdW radii $(1.52,1.75$, 1.85 and $1.98 \AA$ for $\mathrm{O}, \mathrm{Cl}, \mathrm{Br}$ and I, respectively), denotes that medians for $\mathrm{Br}$ and $\mathrm{I}$ are smaller than the sum of the corresponding vdW radii by approximately $0.2 \AA$, indicative of a halogen bond formation (Desiraju et al., 2013). Figure 4A shows the distributions of what we refer to as the "void" distance $\Delta \mathrm{d}_{\mathrm{x} \cdots \mathrm{o}}$, i.e. shortening of halogen to oxygen distance relative to the $\mathrm{vdW}$ radii sum, calculated for all structures for which $\Delta \mathrm{d}_{\mathrm{X} \cdots \mathrm{O}}<0$.

The distribution of halogen-to-oxygen distances shows that the interaction between a chlorine and a carbonyl oxygen is substantially weaker than for bromine and iodine, i.e. $\Delta \mathrm{d}_{\mathrm{Cl} \cdots \mathrm{O}}$ is less negative than $\Delta \mathrm{d}_{\mathrm{Br} \cdots \mathrm{O}}$ and $\Delta \mathrm{d}_{\mathrm{I} \cdots \mathrm{O}}$ $\left(\mathrm{p}_{\mathrm{MW}}=0.003\right.$ and 0.03 , respectively), which do not differ from each other significantly $\left(\mathrm{p}_{\mathrm{KS}}>0.1\right.$, solid lines in Fig. 4A). Correspondingly, $\theta^{\mathrm{x}}(\mathrm{C}-\mathrm{X} \cdots \mathrm{Acc})$ and $\theta^{\mathrm{A}}$ (X -.Acc-C) angles, which define the geometry of an $\mathrm{X}$-bond, differ qualitatively between the three halogen types (Fig. 4B, C). For iodine, the distribution of $\theta^{\mathrm{x}}$ is indicative of the halogen bond formation, while for chlorine and bromine it is much more broadly distributed $\left(\mathrm{p}_{\mathrm{MW}}=3 \cdot 10^{-11}\right.$ and $\left.9 \cdot 10^{-7}\right)$, with minimal difference between the two $\left(\mathrm{p}_{\mathrm{MW}}>0.3 ; \mathrm{p}_{\mathrm{KS}}<0.1\right)$. Moreover, in contrast to iodine, for chlorine and bromine in approximately $25 \%$ of structures the $\theta^{\mathrm{x}}$ angle is smaller than the assumed limit of $140^{\circ}$, and in only about a half of all cases falls within the optimal range of $160-180^{\circ}$ (Fig. 4B).

The sharp maximum in the $\theta^{\mathrm{A}}(\mathrm{X} \cdots$ Acc-C) distribution for iodine, observed as the upcast in the cumulative distribution at $126^{\circ}$ (Fig. 4C), coincides with the optimal halogen-oxygen orientation, provided the spatial distribution of electron density of oxygen in $s p^{2}$ hybridization. The same effect can also be observed for $40 \%$ of carbonyl-bromine contacts $\left(\theta^{\mathrm{A}} \sim 133^{\circ}\right)$, and less evidently for $20 \%$ of carbonyl-chlorine interactions. It should be noted that, despite the minute differences in location, these distributions differ significantly in the shape $\left(\mathrm{p}_{\mathrm{KS}}<0.03\right.$ for $\mathrm{Cl} v$ s. $\mathrm{Br}$, and $\mathrm{p}_{\mathrm{KS}}<0.001$ for $\mathrm{I} v$ s. $\mathrm{Br} / \mathrm{Cl}$ ). Consequently, much narrower distributions are indicative of stronger halogen-carbonyl interaction, i.e. iodine is significantly better X-bond donor than bromine, while virtually no preferences are observed for chlorine. This is better visible, when the restricted set of contacts with $\theta^{\mathrm{x}}>140^{\circ}$ is analyzed (as evidenced by chopped lines in Fig. 4A-C), however due to decreased number of cases, the differences in distributions are less significant.

Statistically, a halogen bond between a carbonyl oxygen and iodine is stronger than that between a carbon$\mathrm{yl}$ and bromine, geometry of which is less restricted to

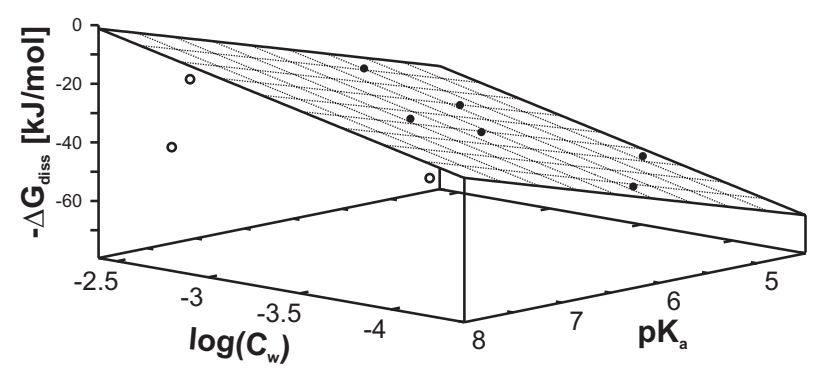

Figure 5. Correlation between the aqueous solubility $(\mathrm{Cw})$ and pKa for dissociation with binding affinity to protein kinase CK2a for a series of nine benzotriazoles halogenated on the benzene ring.

Data for three ligands (open circles), pKa for which is close to the physiological $\mathrm{pH}$, disagree with the general trend.

values optimal for a halogen bond $\left(\theta^{\mathrm{x}} \approx 160-180^{\circ}\right.$ and $\theta^{\mathrm{A}} \approx 120-160^{\circ}$ ), while virtually no propensity for halogen bonding is observed for chlorine.

\section{Short contacts between a halogen atom and a side- chain oxygen}

There are no halogen-type specific differences in either distance or angle distributions of short contacts between a halogen atom and a side-chain oxygen (in all cases $\mathrm{p}_{\mathrm{KS}}>0.1$, Fig. 4D-F). Moreover, the angular preferences of such contacts differ, for each halogen type tested, from that made with a backbone carbonyl (in all cases $\mathrm{p}_{\mathrm{MW}}<0.03$, Fig. $4 \mathrm{~B}, \mathrm{C}$ vs. $\left.4 \mathrm{E}, \mathrm{F}\right)$, suggesting that the backbone carbonyl might be a stronger X-bond acceptor than a side-chain oxygen. These differences cannot be explained by heterogenic hybridization of sidechain oxygen atoms ( $s p^{2}$ for Asn, Asp, Gln and Glu, and $s p^{3}$ for Ser, Thr, Tyr). However, the differences observed for distance distributions are not significant (only for chlorine $\mathrm{p}_{\mathrm{MW}}<0.05$, Fig. 4A vs. 4D).

\section{Short contacts between a halogen atom and a solvent molecule}

The distance distribution between a halogen atom and a proximal solvent molecule resembles trends found for a carbonyl oxygen acting as an X-bond acceptor $\left(\mathrm{p}_{\mathrm{KS}}>0.1\right.$, Fig. $4 \mathrm{G}$ vs. $\left.4 \mathrm{~A}\right)$, however the distribution of the $\theta^{\mathrm{x}}(\mathrm{C}-\mathrm{X} \cdots \mathrm{O})$ angle is visibly broader (for each halogen type $\mathrm{p}_{\text {MW }}<0.0003$, Fig. $4 \mathrm{H}$ vs. 4B). Contrary to the conclusions for contacts with side-chain oxygen, the distance preferences for $\theta^{\mathrm{x}}$ angle depend on the halogen type, and are weaker for chlorine than for the other ones $\left(\mathrm{p}_{\mathrm{MW}}=0.02\right.$ and 0.10 for $\mathrm{Cl} v$ s. $\mathrm{Br}$ and $\mathrm{I}$, respectively). It follows that, if solvent molecules were correctly identified as water, some of them may be regarded as a weak, but noticeable, X-bond acceptors (Fig. 2R-T).

\section{Halogen vs. hydrogen bonding in protein kinase-ligand complexes}

The most known example of a replacement of an $\mathrm{H}$-bond by an X-bond is observed in the recurring pattern of two halogen bonds with backbone carbonyls in the hinge region, which resembles the common mode of ATP-recognition by a protein kinase (pdb1hck; Schulze-Gahmen et al., 1996, Fig. 2Q vs. 2M). Interestingly, the geometry of a halogen bond involving a backbone carbonyl of a protein kinase visibly differs from that observed for a hydrogen bond formed between a backbone carbonyl of a protein kinase and a nitrogen of ei- 
ther halogenated or non-halogenated ligand. The largest differences concern distance between a halogen atom and a carbonyl acceptor, which is approximately $0.3 \AA$ larger than the nitrogen to oxygen distance of $2.87 \AA$ observed for a hydrogen bond, which precisely corresponds to the difference in radii between $\mathrm{N}$ and $\mathrm{X}$ (see Fig. 4I). Broad distributions of the $\theta^{\mathrm{A}}$ angle for halogen bonds are shifted toward the idealized value of $120^{\circ}$, significantly differing from that observed for an $\mathrm{H}$-bond ( $\mathrm{p}_{\mathrm{MW}}<10^{-8}$, Fig. 4C), clearly indicating that the geometry of an $\mathrm{X}$-bond is much more restricted. Moreover, the $\theta^{\mathrm{x}}(\mathrm{C}-\mathrm{X} \cdots \mathrm{O})$ angle qualitatively differs from the $\theta^{\mathrm{D}}(\mathrm{C}-\mathrm{N} \cdots \mathrm{O})$ (see Fig. 1 for definitions). While $\theta^{\mathrm{X}}$ approaches the expected linear configuration, for $\theta^{\mathrm{D}}$ with a ligand nitrogen (found mostly in $s p^{2}$ hybridization) acting as an H-bond donor, the distribution is shifted towards $120^{\circ}$ (Fig. 4B).

In summary, despite the general topological similarity of a halogen and hydrogen bond, geometrical requirements for both are visibly different, so they may not be equivalent when ligands are tightly packed inside the ATP-binding cavity of a protein kinase. A significant contribution of $\mathrm{vdW}$ interactions between atoms neighboring donor and acceptor sites, results in systematic deviation of $\theta^{\mathrm{A}}$ from its optimal value of $120^{\circ}$, expected for the $s p^{2}$ hybridization of the carbonyl oxygen.

\section{Hydrogen bonds formed by halogenated ligands}

More detailed analysis shows that the presence of a halogen atom in the ligand affects the geometry of hydrogen bonds that it forms. The effect is more pronounced for the cases, when a ligand nitrogen forms an H-bond with a protein backbone carbonyl than for those, in which backbone nitrogen acts as an H-bond donor (Fig. 4J-L and 4M-O, red and blue lines vs. black ones). Small differences are observed for $\mathrm{N} \cdots \mathrm{O}$ distance distributions (Fig. 4J and 4M, red vs. black lines), but variations in $\theta^{\mathrm{D}}$ (Fig. $4 \mathrm{~K}, \mathrm{O}$ ) and $\theta^{\mathrm{A}}$ (Fig. 4L, N) are even more remarkable. All these differences are indicative of enhancement of the strength of a hydrogen bond. They are statistically significant when a nitrogen of a halogenated ligand acts as an H-bond donor (Fig. 4J$\left.\mathrm{L} ; \mathrm{P}_{\mathrm{KW}}<0.05\right)$, but not for those in which a ligand oxygen acts as an H-bond acceptor (Fig. 4M-O; $\mathrm{p}_{\mathrm{KW}}<0.05$ only for $\mathrm{N} \cdots \mathrm{O}-\mathrm{C}$ angle). The foregoing supports the trend of $\mathrm{H}$-bond strengthening for halogenated ligands carrying a nitrogen $\mathrm{H}$-bond donor, identified in a larger set of PDB structures (Poznanski et al., 2014), however it is worth noting that the geometry of an H-bond, in which a ligand oxygen is the acceptor, is closer to the idealized geometry than that when a ligand donates an H-bond (Fig. 4N vs. 4L, $\mathrm{P}_{\mathrm{KW}}<0.01$ ).

\section{Electrostatic contribution to ligand binding}

Structure-activity screening of halogenated benzimidazole derivative inhibitors revealed a reasonably good correlation between the inhibitory activity and the change of ligand solvent-accessible surface upon binding (Battistutta et al., 2007), which is indicative of predominance of hydrophobic interactions. However, comparison of binding modes of tetrabromobenzotriazole (TBBt) by two closely related protein kinases: CDK2 (pdb1p5e; De Moliner et al., 2003) and CK2 $\alpha$ (pdb1j91; Battistutta et al., 2001) clearly shows that small differences in charge distribution may result in an alternative mode of TBBt binding (Fig. 2M, N). Similarly, three structurally related ligands: TBBt, tetrabromobenzimidazole (K17, TBBz, pdb2oxy; Battistutta et al., 2007) and pentabromoinda- zole (K64, pdb3kxg; Sarno et al., 2011) bind to CK2 $\alpha$ in different orientations (Fig. 2N-P). Nonetheless, the poses for TBBt with $\mathrm{CDK} 2$ and $\mathrm{TBBz}$ with $\mathrm{CK} 2 \alpha$ are almost identical (Fig. 2M vs. 2O). Altogether, the analysis of protein kinase complexes with halogenated benzimidazoles suggests that subtle electrostatic interactions contribute substantially to ligand binding.

We have systematically explored electrostatic contribution to ligand binding by analyzing the structure-activity relationship for a series of TBBt derivatives (Wasik et al., 2010), in which the $\mathrm{Br}$ at $\mathrm{C}(5)$ of TBBt is replaced by various groups differing in their physicochemical properties, and also for a series of nine bromobenzotriazoles representing all possible patterns of halogenation on the benzene ring (Wasik et al., 2012a). Overall, the hydrophobicity of the monoanionic form of the ligand appeared to be the principal factor governing its inhibitory activity against CK2 $\alpha$ (Wasik et al., 2010; Wasik et al., 2012b). Furthermore, the moderate inhibitory activity exhibited by 4,5,6,7-tetramethylbenzotriazole (Zien et al., 2003), which in contrast to TBBt is in the neutral form at physiological pH (Poznanski et al., 2007), again points to a balance of electrostatic and hydrophobic interactions as an important factor contributing to $\mathrm{CK} 2 \alpha$ inhibition. Accordingly, recent DSC-derived thermodynamic data for binding of TBBt, $\mathrm{TBBz}$ and their close structural analogues to $\mathrm{CK} 2 \alpha$ (Winiewska et al., 2015a; Winiewska et al., 2015b) confirm the predominant contribution of electrostatic and hydrophobic interactions. For ligands that are mostly dissociated (i.e. $\mathrm{p} K_{\mathrm{a}}<6.5$ ), the aqueous solubility and $\mathrm{pK}_{\mathrm{a}}$ for dissociation of the triazole proton together account for more than $95 \%$ of the variance of the free energy of binding determined with the aid of Microscale Thermophoresis (Fig. 5). Three remaining, less dissociated ligands, 4-bromobenzotriazole, 5-bromobenzotriazole and 5,6-dibromobenzotriazole are most probably differently oriented in the ATP binding site, as qualitatively confirmed by tyrosine quenching (Winiewska et al., 2015a).

\section{CONCLUSIONS}

The foregoing analysis clearly shows that in the tightly packed ATP binding pocket of a protein kinase, due to observed significant differences in geometrical preferences, a pattern of $\mathrm{H}$-bonds cannot a priori be replaced by X-bonds. However, the ATP-like H-bonding pattern to the hinge region may be replaced by two parallel $\mathrm{X}$ bonds formed between backbone carbonyl groups and two halogen atoms attached to vicinal carbons of the benzene ring. This interaction with the hinge region (either via halogen or hydrogen bonds), when accompanied by an X-bond formed with the aromatic residue located upstream of the hinge region, may possibly be used to strengthen ligand binding or to enhance ligand selectivity.

Apart from direct effects of halogenation: increased ligand hydrophobicity and possible X-bonding, there are additional effects. These include modulation of the electron density, $\mathrm{p} K_{\mathrm{a}}$ changes of a dissociable group, or strengthening of $\mathrm{H}$-bonds formed between a halogenated ligand and a protein. All these factors affect the binding mode, so that closely related ligands may bind in different orientations, as a result of a subtle balance of electrostatic, hydrogen-bonding and halogen-bonding interactions, with the hydrophobic and electrostatic components predominating. This makes computer-aided drug design for protein kinases extremely challenging. 


\section{Acknowledgements}

This work was supported by the Polish National Science Centre grant 2012/07/B/ST4/01334.

\section{REFERENCES}

Aakeroey CB, Panikkattu S, Chopade PD, Desper J (2013) Competing hydrogen-bond and halogen-bond donors in crystal engineering. Cryst Eng Comm 15: 3125-3136. http://dx.doi.org/10.1039/ C2CE26747K

Anderson TW, Darling DA (1952) Asymptotic theory of certain goodness of fit criteria based on stochastic processes. Ann Math Stat 23: 193-212. http://dx.doi.org/10.1214/aoms/1177729437.

Auffinger P, Hays FA, Westhof E, Ho PS (2004) Halogen bonds in biological molecules. Proc Natl Acad Sci USA 101: 16789-16794. http://dx.doi.org/10.1073/pnas.0407607101.

Barratt E, Bingham RJ, Warner DJ, Laughton CA, Phillips SEV, Homans SW (2005) Van der waals interactions dominate ligand-protein association in a protein binding site occluded from solvent water. J Am Chem Soc 127: 11827-11834. http://dx.doi.org/10.1021/ ja0527525.

Battistutta R, De Moliner E, Sarno S, Zanotti G, Pinna LA (2001) Structural features underlying selective inhibition of protein kinase CK2 by ATP site-directed tetrabromo-2-benzotriazole. Protein Sci 10: 2200-2206. http://dx.doi.org/10.1110/ps.19601.

Battistutta R, Mazzorana M, Sarno S, Kazimierczuk Z, Zanotti G, Pinna LA (2005) Inspecting the structure-activity relationship of protein kinase CK2 inhibitors derived from tetrabromo-benzimidazole. Chem Biol 12: 1211-1219. http://dx.doi.org/10.1016/j.chembiol.2005.08.015.

Battistutta R, Mazzorana M, Cendron L, Bortolato A, Sarno S, Kazimierczuk Z, Zanotti G, Moro S, Pinna LA (2007) The ATP-binding site of protein kinase CK2 holds a positive electrostatic area and conserved water molecules. Chem Bio Chem 8: 1804-1809. http:// dx.doi.org/10.1002/cbic.200700307.

Battistutta R (2009) Structural bases of protein kinase CK2 inhibition. Cell Mol Life Sci 66: 1868-1889. http://dx.doi. org/10.1002/9781118482490.ch1.

Beale TM, Chudzinski MG, Sarwar MG, Taylor MS (2013) Halogen bonding in solution: thermodynamics and applications. Chem Soc Rev 42: 1667-1680. http://dx.doi.org/10.1039/C2CS35213C.

Besant PG, Tan E, Attwood PV (2003) Mammalian protein histidine kinases. Int J Biochem Cell Biol 35: 297-309. http://dx.doi. org $/ 10.1016 /$ S1357-2725(02)00257-1.

Besant PG, Attwood PV (2005) Mammalian histidine kinases. BBAProteins and Proteomics 1754: 281-290. http://dx.doi.org/10.1016/j. bbapap.2005.07.026.

Besant PG, Attwood PV, Piggott MJ (2009) Focus on phosphoarginine and phospholysine. Curr Protein Peptide Sci 10: 536-550. http:// dx.doi.org/10.2174/138920309789630598.

Bogoyevitch MA, Fairlie DP (2007) A new paradigm for protein kinase inhibition: blocking phosphorylation without directly targeting ATP binding. Drug Discov Today 12: 622-633. http://dx.doi.org/10.1016/j. drudis.2007.06.008

Bondi A (1964) van der Waals volumes and radii. J Phys Chem 68: 441451. http://dx.doi.org/10.1021/j100785a001.

Cabrita MT, Vale C, Rauter AP (2010) Halogenated Compounds from Marine Algae. Mar Drugs 8: 2301-2317. doi:10.3390/md8082301.

Carlsson AC, Veiga AX, Erdélyi M (2015) Halogen bonding in solution. Top Curr Chem. http://dx.doi.org/10.1039/C2CS15292D.

Carter M, Ho PS (2011) Assaying the energies of biological halogen bonds. Cryst Growth Des 11: 5087-5095. http://dx.doi.org/10.1021/ $\operatorname{cg} 200991 \mathrm{v}$

Chaikuad A, Tacconi EM, Zimmer J, Liang Y, Gray NS, Tarsounas M, Knapp S (2014) A unique inhibitor binding site in ERK1/2 is associated with slow binding kinetics. Nat Chem Biol 10: 853-860. http://dx.doi.org/10.1038/nchembio.1629.

Ciesla J, Fraczyk T, Rode W (2011) Phosphorylation of basic amino acid residues in proteins: important but easily missed. Acta Biochim Pol 58: 137-147.

Clark T, Hennemann M, Murray JS, Politzer P (2007) Halogen bonding: the sigma-hole. J Mol Model 13: 291-296.

Cohen P (2002) Protein kinases - the major drug targets of the twenty-first century? Nat Rev Drug Discov 1: 309-315. http://dx.doi. org $/ 10.1038 /$ nrd773.

Couty S, Westwood IM, Kalusa A, Cano C, Travers J, Boxall K, Chow CL, Burns S, Schmitt J, Pickard L, Barillari C, McAndrew PC, Clarke PA, Linardopoulos S, Griffin RJ, Aherne GW, Raynaud FI, Workman P, Jones K, van Montfort RL (2013) The discovery of potent ribosomal S6 kinase inhibitors by high-throughput screening and structure-guided drug design. Oncotarget 4: 1647-1661. http:// dx.doi.org/10.18632/oncotarget.1255.
Cowan-Jacob SW, Jahnke W, Knapp S (2014) Novel approaches for targeting kinases: allosteric inhibition, allosteric activation and pseudokinases. Future Med Chem 6: 541-561. http://dx.doi.org/10.4155/ fmc.13.216.

Cozza G, Girardi C, Ranchio A, Lolli G, Sarno S, Orzeszko A, Kazimierczuk Z, Battistutta R, Ruzzene M, Pinna LA (2014) Cell-permeable dual inhibitors of protein kinases CK2 and PIM-1: structural features and pharmacological potential. Cell Mol Life Sci 71: 31733185. http://dx.doi.org/10.1007/s00018-013-1552-5.

Das K, Clark AD, Lewi PJ, Heeres J, de Jonge MR, Koymans LMH, Vinkers HM, Daevaert F, Ludovici DW, Kukla MJ, De Corte B, Kavash RW, Ho CY, Ye H, Lichtenstein MA, Andries K, Pauwels R, de Bethune MP, Boyer PL, Clark P, Hughes SH, Janssen PAJ, Arnold E (2004) Roles of conformational and positional adaptability in structure-based design of TMC125-R165335 (etravirine) and related non-nucleoside reverse transcriptase inhibitors that are highly potent and effective against wild-type and drug-resistant HIV-1 variants. I Med Chem 47: 2550-2560. http://dx.doi.org/10.1021/ jm030558s.

De Moliner E, Brown NR, Johnson LN (2003) Alternative binding modes of an inhibitor to two different kinases. Eur I Biochem 270: 3174-3181. http://dx.doi.org/10.1046/j.1432-1033.2003.03697.x.

DeLano WL, Lam JW (2005) PyMOL: A communications tool for computational models. Abstr Pap Am Chem Soc 230: U1371-U1372. http://dx.doi.org/10.1371/journal.pone.0027543

Desiraju GR, Ho PS, Kloo L, Legon AC, Marquardt R, Metrangolo P, Politzer P, Resnati G, Rissanen K (2013) Definition of the halogen bond (IUPAC Recommendations 2013). Pure Appl Chem 85: 17111713. http://dx.doi.org/10.1351/PAC-REC-12-05-10.

Dietrich J, Hulme C, Hurley LH (2010) The design, synthesis, and evaluation of 8 hybrid DFG-out allosteric kinase inhibitors: A structural analysis of the binding interactions of Gleevec (R), Nexavar (R), and BIRB-796. Biorg Med Chem 18: 5738-5748. http://dx.doi. org/10.1016/j.bmc.2010.05.063.

Dunitz JD (2004) Organic fluorine: Odd man out. Chem Bio Chem 5: 614-621. http://dx.doi.org/10.1002/cbic.200300801.

Eckenhoff RG, Johansson JS (1997) Molecular interactions between inhaled anesthetics and proteins. Pharmacol Rev 49: 343-367.

Elsholz AKW, Turgay K, Michalik S, Hessling B, Gronau K, Oertel D, Maeder U, Bernhardt J, Becher D, Hecker M, Gerth U (2012) Global impact of protein arginine phosphorylation on the physiology of Bacillus subtilis. Proc Natl Acad Sci USA 109: 7451-7456. http://dx.doi.org/10.1073/pnas.1117483109.

Emsley P, Cowtan K (2004) Coot: model-building tools for molecular graphics. Acta Crystallogr Sect D Biol Crystallogr 60: 2126-2132. http://dx.doi.org/10.1107/S0907444904019158.

Emsley P, Lohkamp B, Scott WG, Cowtan K (2010) Features and development of Coot. Acta Crystallogr Sect D Biol Crystallogr 66: 486501. http://dx.doi.org/10.1107/S0907444910007493.

Fabbro D (2015) 25 Years of small molecular weight kinase inhibitors: potentials and limitations. Mol Pharmacol 87: 766-775. http://dx.doi. org $/ 10.1124 / \mathrm{mol} .114 .095489$.

Feng J, Zhu M, Schaub MC, Gehrig P, Roschitzki B, Lucchinetti E, Zaugg M (2008) Phosphoproteome analysis of isoflurane-protected heart mitochondria: phosphorylation of adenine nucleotide translocator-1 on $\operatorname{Tyr}(194)$ regulates mitochondrial function. Cardiovasc Res 80: 20-29. http://dx.doi.org/10.1093/cvr/cvn161.

Fischer PM (2004) The design of drug candidate molecules as selective inhibitors of therapeutically relevant protein kinases. Curr Med Chem 11: 1563-1583. http://dx.doi.org/10.2174/0929867043365062.

Fischmann TO, Smith CK, Mayhood TW, Myers JE, Reichert P, Mannarino A, Carr D, Zhu H, Wong J, Yang RS, Le HV, Madison VS (2009) Crystal structures of MEK1 binary and ternary complexes with nucleotides and inhibitors. Biochemistry 48: 2661-2674. http:// dx.doi.org/10.1021/bi801898e.

Fuhrmann J, Schmidt A, Spiess S, Lehner A, Turgay K, Mechtler K, Charpentier E, Clausen T (2009) McsB Is a protein arginine kinase that phosphorylates and inhibits the heat-shock regulator CtsR. Science 324: 1323-1327. http://dx.doi.org/10.1126/science.1170088.

Garuti L, Roberti M, Bottegoni G (2010) Non-ATP competitive protein kinase inhibitors. Curr Med Chem 17: 2804-2821. http://dx.doi. org/10.2174/092986710791859333.

Goldstein DM, Soth M, Gabriel T, Dewdney N, Kuglstatter A, Arzeno $\mathrm{H}$, Chen J, Bingenheimer W, Dalrymple SA, Dunn J, Farrell R, Frauchiger S, La Fargue J, Ghate M, Graves B, Hill RJ, Li FJ, Litman R, Loe B, McIntosh J, McWeeney D, Papp E, Park J, Reese HF, Roberts RT, Rotstein D, Pablo BS, Sarma K, Stahl M, Sung ML, Suttman RT, Sjogren EB, Tan YC, Trejo A, Welch M, Weller P, Wong BR, Zecic H (2011) Discovery of 6-(2,4-Difluorophenoxy)-2 3-hydroxy-1-(2-hydroxyethyl)propylamino -8-met hyl-8H-pyrido 2,3-d pyrimidin-7-one (Pamapimod) and 6-(2,4-Difluorophenoxy)-8-methyl-2-(tetrahydro-2H-pyran-4-ylamino) pyrido 2,3-d pyrimidin-7(8H)-one (R1487) as orally bioavailable and highly selective inhibitors of p38 alpha mitogen-activated protein kinase. J Med Chem 54: 2255-2265. 
Gower CM, Chang MEK, Maly DJ (2014) Bivalent inhibitors of protein kinases. Crit Rev Biochem Mol Biol 49: 102-115. http://dx.doi.org /10.3109/10409238.2013.875513

Hardegger LA, Kuhn B, Spinnler B, Anselm L, Ecabert R, Stihle M, Gsell B, Thoma R, Diez J, Benz J, Plancher J-M, Hartmann G, Banner DW, Haap W, Diederich F' (2011) Systematic investigation of halogen bonding in protein-ligand interactions. Angew Chem Int Ed 50: 314-318. http://dx.doi.org/10.1002/anie.201006781.

Harrison S, Das K, Karim F, Maclean D, Mendel D (2008) Non-ATPcompetitive kinase inhibitors - enhancing selectivity through new inhibition strategies. Expert Opin Drug Discovery 3: 761-774. http:// dx.doi.org/10.1517/17460441.3.7.761.

Hauchecorne D, van der Veken BJ, Moiana A, Herrebout WA (2010) The $\mathrm{C}-\mathrm{Cl} \cdots \mathrm{N}$ halogen bond, the weaker relative of the $\mathrm{C} \cdots \mathrm{I}$ and C-Br..N halogen bonds, finally characterized in solution. Chem Phys 374: 30-36. http://dx.doi.org/10.1016/j.chemphys.2010.06.004

Hendsch ZS, Tidor B (1994) Do salt bridges stabilize proteins? A continuum electrostatic analysis. Protein Sci 3: 211-226. http://dx.doi. org $/ 10.1002 \% 2 F$ pro. 5560030206

Hernandes MZ, Cavalcanti SMT, Moreira DRM, de Azevedo WF, Jr., Lima Leite AC (2010) Halogen atoms in the modern medicinal chemistry: hints for the drug design. Curr Drug Targets 11: 303-314. http://dx.doi.org/10.2174/138945010790711996.

Howard JAK, Hoy VJ, OHagan D, Smith, GT (1996) How good is fluorine as a hydrogen bond acceptor? Tetrahedron 52: 12613-12622. http://dx.doi.org/10.1016/0040-4020(96)00749-1.

Hubig SM, Lindeman SV, Kochi JK (2000) Charge-transfer bonding in metal-arene coordination. Coord Chem Rev 200: 831-873. http:/9 dx.doi.org/10.1016/S0010-8545(00)00322-2.

Ibrahim MAA (2011) Molecular mechanical study of halogen bonding in drug discovery. I Comput Chem 32: 2564-2574. http://dx.doi. org/10.1002/jcc. 21836 .

Ibrahim MAA (2012) AMBER empirical potential describes the geometry and energy of noncovalent halogen interactions better than advanced semiempirical quantum mechanical method PM6-DH2X. J Phys Chem B 116: 3659-3669. http://dx.doi.org/10.1021/jp3003905.

Joosten RP, Long F, Murshudov GN, Perrakis A (2014) The PDB_ REDO server for macromolecular structure model optimization. IUCrJ 1: 213-220. http://dx.doi.org/10.1107/S2052252514009324.

Jorgensen WL, Schyman P (2012) Treatment of halogen bonding in the OPLS-AA force field: application to potent anti-HIV agents. J Chem Theory Comput 8: 3895-3901. http://dx.doi.org/10.1021/ct300180w.

Khorasanizadeh S (2004) The nucleosome: From genomic organization to genomic regulation. Cell 116: 259-272. http://dx.doi. org/10.1016/S0092-8674(04)00044-3.

Kirkland LO, McInnes C (2009) Non-ATP competitive protein kinase inhibitors as anti-tumor therapeutics. Biochem Pharmacol 77: 1561 1571. http://dx.doi.org/10.1016/j.bcp.2008.12.022

Kleywegt GJ, Harris MR, Zou JY, Taylor TC, Wahlby A, Jones TA (2004) The Uppsala Electron-Density Server. Acta Crystallogr Sect D Biol Crystallogr 60: 2240-2249. http://dx.doi.org/10.1107/ S0907444904013253.

Klumpp S, Krieglstein J (2002) Phosphorylation and dephosphorylation of histidine residues in proteins. Eur J Biochem 269: 1067-1071. http://dx.doi.org/10.1046/j.1432-1033.2002.02755.x.

Kolar M, Hobza P (2012) On extension of the current biomolecular empirical force field for the description of halogen bonds. I Chem Theory Comput 8: 1325-1333. http://dx.doi.org/10.1021/ct2008389.

Koshland DE (1994) The key-lock theory and the induced fit theory. Angew Chem Int Ed 33: 2375-2378. http://dx.doi.org/10.1002/ anie. 199423751

Kraut DA, Churchill MJ, Dawson PE, Herschlag D (2009) Evaluating the potential for halogen bonding in the oxyanion hole of ketosteroid isomerase using unnatural amino acid mutagenesis. ACS Chem Biol 4: 269-273. http://dx.doi.org/10.1021/cb900016q.

Krieger E, Joo K, Lee J, Lee J, Raman S, Thompson J, Tyka M, Baker D, Karplus K (2009) Improving physical realism, stereochemistry, and side-chain accuracy in homology modeling: Four approaches that performed well in CASP8. Proteins: Struct Funct Bioinform 77 114-122. http://dx.doi.org/10.1002\%2Fprot. 22570.

Kruskal WH, Wallis WA (1952) Use of ranks in one-criterion variance analysis. J Amer Statist Assoc 47: 583-621.

Kuglstatter A, Wong A, Tsing S, Lee SW, Lou Y, Villaseñor AG, Bradshaw JM, Shaw D, Barnett JW, Browner MF (2011) Insights into the conformational flexibility of Bruton's tyrosine kinase from multiple ligand complex structures. Protein Sci 20: 428-436. http:// dx.doi.org/10.100/2Fpro. 575

Lamba V, Ghosh I (2012) New directions in targeting protein kinases: focusing upon true allosteric and bivalent inhibitors. Curr Pharm Des 18: 2936-2945. http://dx.doi.org/10.2174/138161212800672813.

Lapek JD, Jr, Tombline G, Kellersberger KA, Friedman MR, Friedman AE (2015) Evidence of histidine and aspartic acid phosphorylation in human prostate cancer cells. Naunyn-Schmiedeberg's Arch Pharmacol 388: 161-173. http://dx.doi.org/10.1007/s00210-014-1063-4.

Lepsik M, Rezac J, Kolar M, Pecina A, Hobza P, Fanfrlik J (2013) The semiempirical quantum mechanical scoring function for in silico drug design. Chem Plus Chem 78: 921-931. http://dx.doi. org/10.1002/cplu.201300199.

Li H, Lu Y, Liu Y, Zhu X, Liu H, Zhu W (2012) Interplay between halogen bonds and pi-pi stacking interactions: CSD search and theoretical study. Phys Chem Chem Phys 14: 9948-9955. http://dx.doi. org/10.1039/c2cp41149k.

Liu Q, Sabnis Y, Zhao Z, Zhang T, Buhrlage SI, Jones LH, Gray NS (2013) Developing irreversible inhibitors of the protein kinase cysteinome. Chem Biol 20: 146-159. http://dx.doi.org/10.1016/j. chembiol.2012.12.006.

Liu RY, Loll PJ, Eckenhoff RG (2005) Structural basis for high-affinity volatile anesthetic binding in a natural 4-helix bundle protein. FASEB J 19: 567-576. http://dx.doi.org/10.1096/fj.04-3171com.

Lu Y-X, Zou J-W, Wang Y-H, Yu Q-S (2006) Bifurcated halogen bonds: An ab initio study of the three-center interactions. I Mol Struct Theochem 767: 139-142. http://dx.doi.org/10.1016/j.theochem.2006.05.024.

Lu YX, Shi T, Wang Y, Yang HY, Yan XH, Luo XM, Jiang HL, Zhu WL (2009) Halogen bonding-a novel interaction for rational drug design? J Med Chem 52: 2854-2862. http://dx.doi.org/10.1021/ jim9000133.

Mann HB, Whitney DR (1947) On a test of whether one of two random variables is stochastically larger than the other. Ann Math Stat 18: 50-60. http://dx.doi.org/10.1214/aoms/1177730491.

Massey FJ (1951) The distribution of the maximum deviation between 2 sample cumulative step functions. Ann Math Stat 22: 125-128.

Matthews HR (1995) Protein-kinases and phosphatases that act on histidine, lysine, or arginine residues in eukaryotic proteins - a possible regulator of the mitogen-activated protein-kinase cascade. Pharmacol Ther 67: 323-350. http://dx.doi.org/10.1016/0163-7258(95)00020-8.

Memic A, Spaller MR (2008) How do halogen substituents contribute to protein-binding interactions? A thermodynamic study of peptide ligands with diverse aryl halides. Chem Bio Chem 9: 2793-2795. http://dx.doi.org/10.1002/cbic.200800572.

Metrangolo P, Neukirch H, Pilati T, Resnati G (2005) Halogen bonding based recognition processes: A world parallel to hydrogen bonding. Acc Chem Res 38: 386-395. http://dx.doi.org/10.1021/ $\operatorname{ar} 0400995$.

Metrangolo P, Meyer F, Pilati T, Resnati G, Terraneo G (2008) Halogen bonding in supramolecular chemistry. Angew Chem Int Ed 47: 6114-6127. http://dx.doi.org/10.1021/cr500674c.

Nazare M, Will DW, Matter H, Schreuder H, Ritter K, Urmann M, Essrich M, Bauer A, Wagner M, Czech J, Lorenz M, Laux V, Wehner V (2005) Probing the subpockets of factor Xa reveals two binding modes for inhibitors based on a 2-carboxyindole scaffold: A study combining structure-activity relationship and X-ray crystallography. J Med Chem 48: 4511-4525. http://dx.doi.org/10.1021/jm0490540.

Niefind K, Raaf J, Issinger OG (2009) Protein kinase CK2: From structures to insights. Cell Mol Life Sci 66: 1800-1816. http://dx.doi. org/10.1007/s00018-009-9149-8.

Novak M, Foroutan-Nejad C, Marek R (2015) Asymmetric bifurcated halogen bonds. Phys Chem Chem Phys 17: 6440-6450. http://dx.doi. org/10.1039/C4CP05532B.

Pannifer ADB, Flint AJ, Tonks NK, Barford D (1998) Visualization of the cysteinyl-phosphate intermediate of a protein-tyrosine phosphatase by X-ray crystallography. I Biol Chem 273: 10454-10462. http://dx.doi.org/10.1074/jbc.273.17.10454.

Parang K, Till JH, Ablooglu AJ, Kohanski RA, Hubbard SR, Cole PA (2001) Mechanism-based design of a protein kinase inhibitor. Nat Struct Biol 8: 37-41. http://dx.doi.org/10.1038/83028.

Parang K, Cole PA (2002) Designing bisubstrate analog inhibitors for protein kinases. Pharmacol Ther 93: 145-157. http://dx.doi. org/10.1016/S0163-7258(02)00184-5.

Parisini E, Metrangolo P, Pilati T, Resnati G, Terraneo G (2011) Halogen bonding in halocarbon-protein complexes: a structural survey. Chem Soc Rev 40: 2267-2278. http://dx.doi.org/10.1039/c0cs00177e.

Pauletti PM, Cintra LS, Braguine CG, da Silva Filho AA, Andrade e Silva ML, Cunha WR, Januario AH (2010) Halogenated indole alkaloids from marine invertebrates. Mar Drugs 8: 1526-1549. http:// dx.doi.org $/ 10.3390 / \mathrm{md} 8051526$.

Persch E, Dumele O, Diederich F (2015) Molecular recognition in chemical and biological systems. Angew Chem Int Ed 54: 3290-3327. http://dx.doi.org/10.1002/anie.201408487.

Pflug A, Johnson KA, Engh RA (2012) Anomalous dispersion analysis of inhibitor flexibility: a case study of the kinase inhibitor H-89. Acta Crystallogr Sect F Struct Biol Cryst Commun 68: 873-877. http:// dx.doi.org/10.1107/S1744309112028655.

Politzer P, Murray JS, Concha MC (2007) Halogen bonding and the design of new materials: organic bromides, chlorides and perhaps even fluorides as donors. J Mol Model 13: 643-650. http://dx.doi. org/10.1007/s00894-007-0176-9.

Poznanski J, Najda A, Bretner M, Shugar D (2007) Experimental (C-13 NMR) and theoretical (ab initio molecular orbital calculations) studies on the prototropic tautomerism of benzotriazole and some derivatives symmetrically substituted on the benzene ring. J Phys Chem A 111: 6501-6509. http://dx.doi.org/10.1021/jp071611h. 
Poznanski J, Shugar D (2013) Halogen bonding at the ATP binding site of protein kinases: Preferred geometry and topology of ligand binding. BBA-Proteins and Proteomics 1834: 1381-1386. http://dx.doi. org/10.1016/j.bbapap.2013.01.026.

Poznanski J, Poznanska A, Shugar D (2014) A protein data bank survey reveals shortening of intermolecular hydrogen bonds in ligand-protein complexes when a halogenated ligand is an H-bond donor. PLoS One 9: e99984. http://dx.doi.org/10.1371/journal. pone.0099984.

Reddy DS, Craig DC, Desiraju GR (1996) Supramolecular synthons in crystal engineering. 4. Structure simplification and synthon interchangeability in some organic diamondoid solids. I Am Chem Soc 118: 4090-4093. http://dx.doi.org/10.1021/ja953373m.

Rendine S, Pieraccini S, Forni A, Sironi M (2011) Halogen bonding in ligand-receptor systems in the framework of classical force fields. Phys Chem Chem Phys 13: 19508-19516. http://dx.doi.org/10.1039/ c1cp22436k.

Richardson CM, Williamson DS, Parratt MJ, Borgognoni J, Cansfield AD, Dokurno P, Francis GL, Howes R, Moore JD, Murray JB, Robertson A, Surgenor AE, Torrance CJ (2006) Triazolo[1,5-a]pyrimidines as novel CDK2 inhibitors: protein structure-guided design and SAR. Bioorg Med Chem Lett 16: 1353-1357. http://dx.doi. org/10.1016/j.bmcl.2005.11.048.

Robarge KD, Lee W, Eigenbrot C, Ultsch M, Wiesmann C, Heald R, Price S, Hewitt J, Jackson P, Savy P, Burton B, Choo EF, Pang J, Boggs J, Yang A, Yang X, Baumgardner M (2014) Structure based design of novel 6,5 heterobicyclic mitogen-activated protein kinase kinase (MEK) inhibitors leading to the discovery of imidazo[1,5-a] pyrazine G-479. Bioorg Med Chem Lett 24: 4714-4723. http://dx.doi. org/10.1016/j.bmcl.2014.08.008.

Rosokha SV, Kochi JK (2008) X-ray structures and electronic spectra of the pi-halogen complexes between halogen donors and acceptors with pi-receptors. Halogen Bonding: Fundamentals and Applications 126: 137-160.

Sarno S, Papinutto E, Franchin C, Bain J, Elliott M, Meggio F, Kazimierczuk Z, Orzeszko A, Zanotti G, Battistutta R, Pinna LA (2011) ATP site-directed inhibitors of protein kinase CK2: an update. Curr Top Med Chem 11: 1340-1351. http://dx.doi. org/10.2174/156802611795589638.

Sarwar MG, Dragisic B, Salsberg LJ, Gouliaras C, Taylor MS (2010) Thermodynamics of halogen bonding in solution: substituent, structural, and solvent effects. J Am Chem Soc 132: 1646-1653. http:// dx.doi.org/10.1021/ja9086352.

Scholfield MR, Vander Zanden CM, Carter M, Ho PS (2013) Halogen bonding (X-bonding): A biological perspective. Protein Sci 22: 139-152. http://dx.doi.org/10.1002/pro.2201.

Schulze-Gahmen U, DeBondt HL, Kim SH (1996) High-resolution crystal structures of human cyclin-dependent kinase 2 with and without ATP: Bound waters and natural ligand as guides for inhibitor design. J Med Chem 39: 4540-4546. 10.1021/jm960402a.

Smit AJ (2004) Medicinal and pharmaceutical uses of seaweed natural products: A review. J Appl Phycol 16: 245-262. http://dx.doi. org/10.1023/B:JAPH.0000047783.36600.ef.

Steeg PS, Palmieri D, Ouatas T, Salerno M (2003) Histidine kinases and histidine phosphorylated proteins in mammalian cell biology, signal transduction and cancer. Cancer Lett 190: 1-12 http://dx.doi. org/10.1016/S0304-3835(02)00499-8.

Steinig AG, Li AH, Wang J, Chen X, Dong H, Ferraro C, Jin M, Kadalbajoo M, Kleinberg A, Stolz KM, Tavares-Greco PA, Wang T, Albertella MR, Peng Y, Crew L, Kahler J, Kan J, Schulz R, Cooke A, Bittner M, Turton RW, Franklin M, Gokhale P, Landfair D, Mantis C, Workman J, Wild R, Pachter J, Epstein D, Mulvihill MJ (2013) Novel 6-aminofuro[3,2-c]pyridines as potent, orally efficacious inhibitors of cMET and RON kinases. Bioorg Med Chem Lett 23: 4381-4387. http://dx.doi.org/10.1016/j.bmcl.2013.05.074

Tong YS, Lin NH, Wang L, Hasvold L, Wang WB, Leonard N, Li TM, Li Q, Cohen J, Gu WZ, Zhang HY, Stoll V, Bauch J, Marsh K, Rosenberg SH, Sham HL (2003) Discovery of potent imidazole and cyanophenyl containing farnesyltransferase inhibitors with improved oral bioavailability. Bioorg Med Chem Lett 13: 1571-1574. http://dx.doi.org/10.1016/S0960-894X(03)00195-1.

Ventimig.Fa, Wool IG (1974) Kinase that transfers gamma-phosphoryl group of gtp to proteins of eukaryotic $40 \mathrm{~s}$ ribosomal-subunits. Proc Natl Acad Sci USA 71: 350-354.

Voth AR, Hays FA, Ho PS (2007) Directing macromolecular conformation through halogen bonds. Proc Natl Acad Sci USA 104: 61886193. http://dx.doi.org/10.1073/pnas.0610531104.

Voth AR, Ho PS (2007) The role of halogen bonding in inhibitor recognition and binding by protein kinases. Curr Top Med Chem 7: 1336-1348. http://dx.doi.org/10.2174/156802607781696846.
Voth AR, Khuu P, Oishi K, Ho PS (2009) Halogen bonds as orthogonal molecular interactions to hydrogen bonds. Nat Chem 1: 74-79. http://dx.doi.org/10.1038/nchem.112.

Wagner PD, Vu ND (2000) Histidine to aspartate phosphotransferase activity of $\mathrm{nm} 23$ proteins: phosphorylation of aldolase $C$ on Asp-319. Biochem J 346: 623-630. http://dx.doi.org/10.1042/02646021:3460623.

Wang L, Gao J, Bi F, Song B, Liu C (2014) Toward the development of the potential with angular distortion for halogen bond: a comparison of potential energy surfaces between halogen bond and hydrogen bond. I Phys Chem A 118: 9140-9147. http://dx.doi. org/10.1021/jp502739c.

Wang W, Okada Y, Shi HB, Wang YQ, Okuyama T (2005) Structures and aldose reductase inhibitory effects of bromophenols from the red alga Symphyocladia latiuscula. J Nat Prod 68: 620-622. http:// dx.doi.org/10.1021/np040199j.

Wasik R, Lebska M, Felczak K, Poznanski J, Shugar D (2010) Relative role of halogen bonds and hydrophobic interactions in inhibition of human protein kinase CK2 alpha by tetrabromobenzotriazole and some c(5)-substituted analogues. J Phys Chem B 114: 10601-10611. http://dx.doi.org/10.1021/ip102848y.

Wasik R, Winska P, Poznanski J, Shugar D (2012a) Synthesis and physico-chemical properties in aqueous medium of all possible isomeric bromo analogues of benzo-1H-triazole, potential inhibitors of protein kinases. I Phys Chem B 116: 7259-7268. http://dx.doi. org/10.1021/jp301561x.

Wasik R, Winska P, Poznanski J, Shugar D (2012b) Isomeric mono, di-, and tri-bromobenzo-1H-triazoles as inhibitors of human protein kinase CK2 alpha. PLoS One 7: e48898. http://dx.doi.org/10.1371/ journal.pone.0048898.

Wenglowsky S, Ren L, Ahrendt KA, Laird ER, Aliagas I, Alicke B, Buckmelter AJ, Choo EF, Dinkel V, Feng B, Gloor SL, Gould SE, Gross S, Gunzner-Toste J, Hansen JD, Hatzivassiliou G, Liu B, Malesky K, Mathieu S, Newhouse B, Raddatz NJ, Ran Y, Rana S, Randolph N, Risom T, Rudolph J, Savage S, Selby LT, Shrag M, Song K, Sturgis HL, Voegtli WC, Wen Z, Willis BS, Woessner RD, Wu WI, Young WB, Grina J (2011) Pyrazolopyridine inhibitors of B-Raf(V600E). Part 1: the development of selective, orally bioavailable, and efficacious inhibitors. ACS Med Chem Lett 2: 342-347. http://dx.doi.org/10.1021/ml200025q

Wilcken R, Zimmermann MO, Lange A, Joerger AC, Boeckler FM (2013) Principles and applications of halogen bonding in medicinal chemistry and chemical biology. J Med Chem 56: 1363-1388. http:// dx.doi.org/10.1021/jm3012068.

Winiewska M, Kucińska K, Makowska M, Poznański J, Shugar D (2015a) Thermodynamics parameters for binding of halogenated benzotriazole inhibitors of human protein kinase CK2 $\alpha$. Biochim Biophys Acta. http://dx.doi.org/10.1016/j.bbapap.2015.04.004.

Winiewska M, Makowska M, Maj P, Wielechowska M, Bretner M, Poznanski J, Shugar D (2015b) Thermodynamic parameters for binding of some halogenated inhibitors of human protein kinase CK2. Biochem Biophys Res Commun 456: 282-287. http://dx.doi. org/10.1016/j.bbrc.2014.11.072.

Yasuda H, Park E, Yun CH, Sng NJ, Lucena-Araujo AR, Yeo WL, Huberman MS, Cohen DW, Nakayama S, Ishioka K, Yamaguchi N, Hanna M, Oxnard GR, Lathan CS, Moran T, Sequist LV, Chaft JE, Riely GJ, Arcila ME, Soo RA, Meyerson M, Eck MJ, Kobayashi SS, Costa DB (2013) Structural, biochemical, and clinical characterization of epidermal growth factor receptor (EGFR) exon 20 insertion mutations in lung cancer. Sci Transl Med 5: 216ra177. http://dx.doi. org/10.1126/scitranslmed.3007205.

Zhang JM, Yang PL, Gray NS (2009) Targeting cancer with small molecule kinase inhibitors. Nat Rev Cancer 9: 28-39. http://dx.doi. org/10.1038/nrc2559.

Zhao Z, Wu H, Wang L, Liu Y, Knapp S, Liu QS, Gray NS (2014) Exploration of type II binding mode: a privileged approach for kinase inhibitor focused drug discovery? ACS Chem Biol 9: 12301241. http://dx.doi.org/10.1021/cb500129t.

Zien P, Bretner M, Zastapilo K, Szyszka R, Shugar D (2003) Selectivity of 4,5,6,7-tetrabromobenzimidazole as an ATP-competitive potent inhibitor of protein kinase CK2 from various sources. Biochem Biophys Res Commun 306: 129-133. http://dx.doi.org/10.1016/S0006$291 \mathrm{X}(03) 00928-8$.

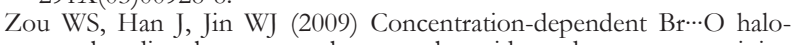
gen bonding between carbon tetrabromide and oxygen-containing organic solvents. J Phys Chem A 113: 10125-10132. http://dx.doi. org/10.1021/jp905914q. 